\title{
ATP synthesis in the energy metabolism pathway: a new perspective for manipulating CdSe quantum dots biosynthesized in Saccharomyces cerevisiae
}

This article was published in the following Dove Press journal:

International Journal of Nanomedicine

19 May 2017

Number of times this article has been viewed

\author{
Rong Zhang ${ }^{1-3}$ \\ Ming Shao ${ }^{1-3}$ \\ Xu Han ${ }^{1-3}$ \\ Chuan Wang ${ }^{3-4}$ \\ Yong $\mathrm{Li}^{3-4}$ \\ Bin $\mathrm{Hu}^{3-4}$ \\ Daiwen Pang ${ }^{3-4}$ \\ Zhixiong $\mathrm{Xie}^{1-3}$
}

'Hubei Key Laboratory of Cell Homeostasis, ${ }^{2}$ College of Life Sciences, Wuhan University, ${ }^{3} \mathrm{Key}$ Laboratory of Analytical Chemistry for Biology and Medicine (Ministry of Education), ${ }^{4}$ College of Chemistry and Molecular Science, Wuhan University,

Wuhan, People's Republic of China
Correspondence: Zhixiong Xie College of Life Sciences, Wuhan University, 299 Bayi Road, Wuhan 430072, People's Republic of China Tel +862768752090 $\mathrm{Fax}+862768752560$

Email zxxie@whu.edu.cn

\begin{abstract}
Due to a growing trend in their biomedical application, biosynthesized nanomaterials are of great interest to researchers nowadays with their biocompatible, low-energy consumption, economic, and tunable characteristics. It is important to understand the mechanism of biosynthesis in order to achieve more efficient applications. Since there are only rare studies on the influences of cellular energy levels on biosynthesis, the influence of energy is often overlooked. Through determination of the intracellular ATP concentrations during the biosynthesis process, significant changes were observed. In addition, ATP synthesis deficiency caused great decreases in quantum dots (QDs) biosynthesis in the $\Delta a t p 1, \Delta a t p 2, \Delta a t p 14$, and $\Delta a t p 17$ strains. With inductively coupled plasma-atomic emission spectrometry and atomic absorption spectroscopy analyses, it was found that ATP affected the accumulation of the seleno-precursor and helped with the uptake of $\mathrm{Cd}$ and the formation of QDs. We successfully enhanced the fluorescence intensity 1.5 or 2 times through genetic modification to increase ATP or SeAM (the seleno analog of $S$-adenosylmethionine, the product that would accumulate when ATP is accrued). This work explains the mechanism for the correlation of the cellular energy level and QDs biosynthesis in living cells, demonstrates control of the biosynthesis using this mechanism, and thus provides a new manipulation strategy for the biosynthesis of other nanomaterials to widen their applications.
\end{abstract}

Keywords: ATP, biosynthesis, Saccharomyces cerevisiae, QDs, CdSe

\section{Introduction}

Nanomaterials, ${ }^{1}$ due to their unique properties, have been widely used in cell imaging, ${ }^{2,3}$ diagnosis, ${ }^{4,5}$ biosensing, ${ }^{6,7}$ electro-optic device, ${ }^{8}$ and so on, especially on medical imaging because of their (surface modified nanomaterials) high biocompatibility to cells. Thus, tremendous interest has arisen in the synthesis of well-dispersed and uniform-sized nanomaterials..$^{9,10}$ Nanoparticles biosynthesized by organisms, without involving the toxic solvents, strict conditions, or expensive processes that are needed in chemical methods, have become a popular subject. ${ }^{11}$ Various nanoparticles are reported that are biosynthesized by bacteria, ${ }^{12-14}$ fungi, ${ }^{15,16}$ plants, ${ }^{17,18}$ mammalian cells, ${ }^{19}$ or even earthworms. ${ }^{20}$ Considering the simple culture methods, the low cost of the equipment, and the easy way to get the gradients, the biosynthesis of nanoparticles using microorganisms is the most economic and common approach.

There have been many investigations on the biosynthesis of nanomaterials, mainly concerning their applications. ${ }^{21}$ In order to obtain nanoparticles with a defined expectation in the biosynthesis, whether through optimizing the culture conditions or adjusting the concentrations of primary substrates, former studies were devoted 
to manipulating the biosynthesis by extrinsic factors, and few were on the intrinsic characters of the microorganisms applied in the biosynthesis. Ayano et $\mathrm{al}^{22}$ found that the optimal culture conditions to biosynthesize CdSe nanoparticles by Pseudomonas aeruginosa were when the cells were cultured at $25^{\circ} \mathrm{C}-40^{\circ} \mathrm{C}, 0.05-10 \mathrm{~g} \mathrm{~L}^{-1}$ of $\mathrm{NaCl}$ concentration, and neutral $\mathrm{pH}$. According to Gericke and Pinches, ${ }^{23}$ the size and shape of gold nanoparticles biosynthesized by fungus could be manipulated by changing crucial growth parameters. They successfully obtained spherical, hexagonal, and triangular-shaped nanoparticles with different sizes through culturing under various $\mathrm{pH}$ and temperature conditions. Besides the studies of the adscititious substances and the culture conditions, there have also been some studies focused on the intrinsic metabolisms of the bioreactor used in the biosynthesis. For example, for $\mathrm{Sb}_{2} \mathrm{O}_{3}$ nanoparticles biosynthesized by yeast, reported by Jha et al, ${ }^{24}$ it was suggested that the membrane-bound and cytosolic oxidoreductases and quinines might be the key influential factors of the process. Phenol oxidases in the Lentinus edodes were proved to be responsible for the biosynthesis of $\mathrm{Au}$ nanoparticles. ${ }^{25}$ In general, current research has mostly focused on the culture conditions or the substances, while the role of energy has hardly been mentioned.

In the previous work of our laboratory, we constructed a convenient way to biosynthesize CdSe quantum dots (QDs) with baker's yeast Saccharomyces cerevisiae ${ }^{26}$ and then promoted the QDs production by genetic modification. ${ }^{27}$ Glutathione (L- $\gamma$-glutamylcysteinylglycine, GSH) was found to be a vital compound in the biosynthesis of CdSe QDs, the intracellular content of which showed synchronized increase with the fluorescence intensities when seleniumized cells were initially incubated with $\mathrm{CdCl}_{2} \cdot{ }^{27}$ Besides the substances that assisted with the biosynthesis of CdSe QDs, GO (gene ontology) analysis revealed that the proteins that encapsulated the CdSe QDs biosynthesized by yeast mostly functioned in cell energy metabolism (unpublished data); thus, this may indicate that energy has a noticeable role in the process. There may be a need for not only micromolecular polypeptides (such as GSH) ${ }^{27}$ but also cell energy to ensure the ambient temperature and strict conditions for the stable biosynthesis of CdSe QDs with good dispersal and uniformity. With its favorable biocompatibility characteristic, the system was successfully applied to construct a cell beacon using Staphylococcus aureus as a bioreactor. ${ }^{28}$

Figuring out the actual role that energy plays in the biosynthesis would be conducive to further understanding of the mechanism. ${ }^{26,27}$ The present study used the concentrations of intracellular ATP (the most commonly used direct energy resource) and fluorescence intensities as indicators to investigate the influences of energy on the biosynthesis of CdSe QDs in yeast. Intracellular Se or Cd concentrations were checked during the cell-seleniumized phase or the crystallization phase $^{26}$ with inductively coupled plasma-atomic emission spectrometry (ICP-AES) and atomic absorption spectroscopy (AAS) to confirm the influences on the absorption of the substrates and the crystallization of CdSe QDs. Finally, the fluorescence intensities were improved by genetic modification of the ATP metabolism pathway. In consequence, the biosynthesis can be controlled with defined expectation and it can be used as guidance for the biosynthesis of other similar nanoparticles with yeast or other microorganisms. The present work provides a new perspective for future research on the biosynthesis mechanisms of nanomaterials and makes it easier to convert the biosynthesized nanomaterials into applications.

\section{Materials and methods}

\section{Strains and media}

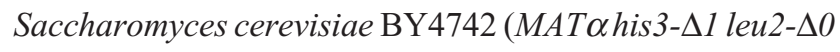
lys 2- $\Delta 0$ ura3- $\Delta 0$ ) (wild-type, WT) and the $\Delta a t p 1, \Delta a t p 2$, $\Delta a t p 14, \Delta a t p 17, \Delta p f k 1$, and $\Delta r g t 2$ mutant strains were obtained from the European Saccharomyces cerevisiae Archive for Functional Analysis (Bad Homburg, Germany) (all strain information is listed in Table $\mathrm{S} 1$ ). The $\mathrm{P}_{G A L 1}-A D K 1$ and $\mathrm{P}_{G A L I}-S A M 2$ strains were constructed in this study (Table S2). Strains were cultured in $1 \mathrm{~g} \mathrm{~L}^{-1}$ yeast extract and $2 \mathrm{~g} \mathrm{~L}^{-1}$ peptone (YP), supplied with $2 \mathrm{~g} \mathrm{~L}^{-1}$ glucose (YPGlu) or YP supplied with $2 \mathrm{~g} \mathrm{~L}^{-1}$ galactose (YPGal) media. Unless otherwise indicated, the reagents used in the present work were obtained from the Sinopharm Chemical Reagent Co. (Shanghai, China).

\section{Biosynthesis of CdSe QDs}

The biosynthesis of CdSe QDs with yeast was performed according to the previous study, ${ }^{26}$ with a slight adjustment, as follows: stationary phase cells were co-incubated with $\mathrm{Na}_{2} \mathrm{SeO}_{3}$ at a final concentration of $2.5 \mathrm{mM}$ for 24 hours to get seleniumized (hereafter referred to as seleniumized cells), and then the cells were collected by centrifugation at $3,000 \mathrm{~g}$ for $1 \mathrm{~min}$. The cell pellets were resuspended in an equal volume of fresh medium and then co-incubated with $\mathrm{CdCl}_{2}$ at a final concentration of $1 \mathrm{mM}$ to synthesize CdSe QDs (the biosynthesis procedure was presented in Figure S1). After incubation for 24 hours, the fluorescence intensity was measured. The cells were cultivated under $30^{\circ} \mathrm{C}$ at 200 
revolutions per minute (rpm) (cells' growing curves are shown in Figure S2).

To avoid influences of the cell biomass, all the cultures were adjusted to the same cell density (optical density $[\mathrm{OD}]_{600}=12.0$ ) before co-incubating with $\mathrm{Na}_{2} \mathrm{SeO}_{3}$.

\section{Intracellular CdSe QD fluorescence intensity measurement}

Cell samples were collected after biosynthesis for fluorescence measurement (with the $\mathrm{OD}_{600}$ of 6.0) and washed with $1 \mathrm{~mL}$ of $1 \times$ phosphate-buffered saline (PBS, $\mathrm{pH} 7.5$ ) and then resuspended with $1 \mathrm{~mL}$ of $1 \times \mathrm{PBS}(\mathrm{pH} 7.5)$ before fluorescence intensity determination. The intracellular $\mathrm{CdSe}$ QDs fluorescence intensity was calculated by subtraction of the cellular autofluorescence (seleniumized cells) from the total fluorescence. All fluorescence spectra of the cells synthesizing QDs and seleniumized cells were acquired with a Cytation3 Multi-mode Reader from BioTek (Winooski, VT, USA), with an excitation wavelength of $400 \mathrm{~nm}$ and the detection emission spectrum of 450 to $700 \mathrm{~nm}$.

\section{Determination of intracellular ATP levels}

Samples of $1 \times 10^{7}$ cells $\left(\mathrm{OD}_{600}=1.0\right)$ were harvested and washed with $200 \mu \mathrm{L}$ sterilized ice-cold deionized water three times. Then, cell pellets were resuspended in $500 \mu \mathrm{L}$ of ATP determination lysis solution and transferred to $2 \mathrm{~mL}$ snap-cap tubes with $0.5 \mathrm{~g}$ glass beads (425-600 $\mu \mathrm{m}$ in diameter; Sigma, St Louis, MO, USA). Cells were ruptured with a Mini-Bead beater-16 (BioSpec, Bartlesville, OK, USA) for $1 \mathrm{~min}$ on and $1 \mathrm{~min}$ pause on ice to dissipate heat, and repeated for two times. Then, the tubes were centrifuged at $16,000 \mathrm{~g}$, at $4^{\circ} \mathrm{C}$, for $5 \mathrm{~min}$, and the supernatants were collected in new centrifuge tubes. Samples were then processed and intracellular ATP concentrations were determined as described in the protocol of the ATP Assay Kit (S0026; Beyotime, Shanghai, China) with a Cytation3 Multi-mode Reader from BioTek.

\section{Determination of intracellular GSH levels}

Samples of $1 \times 10^{7}$ cells $\left(\mathrm{OD}_{600}=1.0\right)$ were centrifuged and harvested, and then the pellets were washed with $200 \mu \mathrm{L}$ of sterilized ice-cold $1 \times \mathrm{PBS}(\mathrm{pH} 7.5)$ two times. The cell pellets were resuspended with $160 \mu \mathrm{L}$ of sterilized ice-cold deionized water, followed by the addition of $160 \mu \mathrm{L}$ of sterilized icecold $20 \mathrm{mM} \mathrm{HCl}$ and $80 \mu \mathrm{L}$ of sterilized ice-cold $5 \%$ (wt/vol) 5 -sulfosalicylic acid. The suspensions were transferred to $2 \mathrm{~mL}$ snap-cap tubes with $0.5 \mathrm{~g}$ acid-washed glass beads, and the cells were ruptured with a Mini-Bead beater-16 (BioSpec) for $1 \mathrm{~min}$ on and $2 \mathrm{~min}$ pause on ice, and repeated once.
Then, the tubes were centrifuged at $13,000 \mathrm{~g}$, at $4^{\circ} \mathrm{C}$, for $15 \mathrm{~min}$, and the supernatants were collected in new centrifuge tubes. Samples were then processed and the intracellular GSH concentrations were measured as described in the protocol of the Total Glutathione Assay Kit (S0052; Beyotime) by a Cytation3 Multi-mode Reader from BioTek.

\section{ICP-AES and AAS analysis}

Cell suspensions $(2 \mathrm{~mL})$ were centrifuged at $5,000 \mathrm{~g}$ for $3 \mathrm{~min}$, and then the supernatants were collected in centrifuge tubes before filtering with a $0.22-\mu \mathrm{m}$ filter unit (Merck Millipore, Billerica, MA, USA). $\mathrm{HNO}_{3}$ and water (Milli-Q, 18.2 M $\Omega$; Merck Millipore) were added to the solutions to get a final concentration of $1 \%(\mathrm{vol} / \mathrm{vol})$, and the samples were stored at $4^{\circ} \mathrm{C}$ until needed. The cell pellets were collected and washed with ice-cold $1 \times$ PBS before resuspension with $500 \mu \mathrm{L}$ of water (Milli-Q, 18.2 M $\Omega$ ), and then transferred to polytetrafluoroethylene reactors. After $2 \mathrm{~mL}$ of $\mathrm{HNO}_{3}$ had been added to the samples, they were placed on a heating plate at $120^{\circ} \mathrm{C}$ for 2 hours and then at $90^{\circ} \mathrm{C}$ until the residues were around $100 \mu \mathrm{L} . \mathrm{HNO}_{3}(1 \%, \mathrm{vol} / \mathrm{vol})$ was added to make a total volume of $1 \mathrm{~mL}$ and diluted to $10 \mathrm{~mL}$ with water (Milli-Q, 18.2 M 2 ) prior to determination. The Se concentrations in the supernatants or inside the cells were determined with ICP-AES (IRIS II; Thermo Fisher Scientific, Fair Lawn, NJ, USA). The Cd concentrations were characterized using AAS with a ContrAA 700 high-resolution continuous light source atomic absorption spectrophotometer (Analytik Jena, Jena, Germany).

\section{Seleno-compounds separation and characterization}

A wet weight of $0.5 \mathrm{~g}$ seleniumized cells was collected and washed with $1 \times$ PBS ( $\mathrm{pH} 7.5$ ), and the cell pellet was then resuspended with $1 \times$ PBS $(\mathrm{pH} 7.5)$. Cells were disrupted with a Mini-Bead beater-16 (BioSpec) for $1 \mathrm{~min}$ on and 2 min pause on ice, twice. Samples were centrifuged to get the lysate, the protein concentrations of the samples were determined by the Bradford method, ${ }^{29}$ and then adjusted to the same value in all samples. Trypsin $(100 \mathrm{mg}$ ) (Amersco, Solon, OH, USA) and TCS buffer $(10 \times, 0.1 \mathrm{M}$ Tris-Cl, $\mathrm{pH} 7.5,10 \mathrm{mM} \mathrm{CaCl}_{2}, 0.5 \% \mathrm{SDS}$ ) were added to the samples and then they were incubated at $37^{\circ} \mathrm{C}$ for $20 \mathrm{~h}$. After centrifugation, the supernatants were collected and filtered with $0.22-\mu \mathrm{m}$ filter units. Then, the samples were subjected to step-by-step ultrafiltration with $100 \mathrm{KD}, 50 \mathrm{KD}, 10 \mathrm{KD}$, and $3 \mathrm{KD}$ Millipore ultrafiltration tubes at 4,500 rpm for $15 \mathrm{~min}$. Then, the prepared samples were used for high-performance 
liquid chromatography (HPLC) with ICP mass spectrometry (MS) (HPLC-ICP-MS) measurement, which was performed on an Agilent 7500 ICP-MS system (Agilent, Santa Clara, CA, USA), coupled with a HPLC system (Shimadzu, Kyoto, Japan) equipped with a CAPCELL PAK C18 column (Shiseido, Tokyo, Japan).

\section{Improving the biosynthesis of CdSe QDs}

The promoter of gene $A D K 1$ or $S A M 2$ was replaced with a stronger promoter, $\mathrm{P}_{G A L I}$, through homologous recombination (details of the construction process are in Supplementary materials) to get overexpression. The modified strains were used to biosynthesize CdSe QDs cultured in YPGal medium (with galactose as an inducer of the overexpression).

\section{Statistical analysis}

All statistical analyses were performed using Origin 2016. The schematic diagram was made with Photoshop CC. Graph data are presented as means and SD. Two-sample $t$-tests were used on the data where appropriate.

\section{Results}

\section{Intracellular ATP concentrations during yeast QDs biosynthesis}

To confirm the influence of cellular ATP levels on the CdSe QDs biosynthesis in S. cerevisiae, cells of different processing stages of CdSe QDs biosynthesis were collected to determine the concentrations of intracellular ATP. The intracellular ATP concentrations of the WT cells were measured during a 12-hour incubation with $\mathrm{Na}_{2} \mathrm{SeO}_{3}$ at a final concentration of $2.5 \mathrm{mM}$; a sharp peak appeared at 2 hours after the introduction of $\mathrm{Na}_{2} \mathrm{SeO}_{3}$ into the culture (Figure 1A). Starting from the exponential phase, the ATP concentrations of the sample cells all sharply increased right after either $\mathrm{Na}_{2} \mathrm{SeO}_{3}$ or $\mathrm{CdCl}_{2}$ was added to the culture, and then rapidly reduced. The ATP concentrations of the control group remained stable, with a slight fluctuation at 24- to 48-hour cultivation; and after the cells were transformed to fresh medium at 48 hours, the concentrations decreased at first and then increased substantially. Clearly, the intracellular ATP concentrations had obvious changes during the process of QDs biosynthesis in the sample cells, while the control group had no such changes (Figure 1B).

\section{CdSe QDs biosynthesis under low ATP synthesis conditions}

To inspect the relation between ATP synthesis and CdSe QDs biosynthesis, several ATP-synthesis-deficient strains were introduced. S. cerevisiae strain $\Delta a t p 1$ displays a complete loss of ATP synthase activity. ${ }^{30}$ The determination of the intracellular ATP concentration, with half the value of WT cells, proved that the $\Delta a t p 1$ strain was deficient in ATP synthesis (Figure 2). The fluorescence intensity of $\Delta a t p 1$ was just a quarter of that in the WT cells (Figure 2), which was consistent with the ATP concentration changes of the two strains. Other gene knock-out strains that were deficient in ATP synthesis, $\Delta a t p 2,{ }^{31} \Delta a t p 14,{ }^{32}$ and $\Delta a t p 17,{ }^{33}$ were also applied in the synthesis of QDs to further confirm the results, with an outcome concurrent with that for the $\Delta a t p 1$ strain, namely much lower intracellular
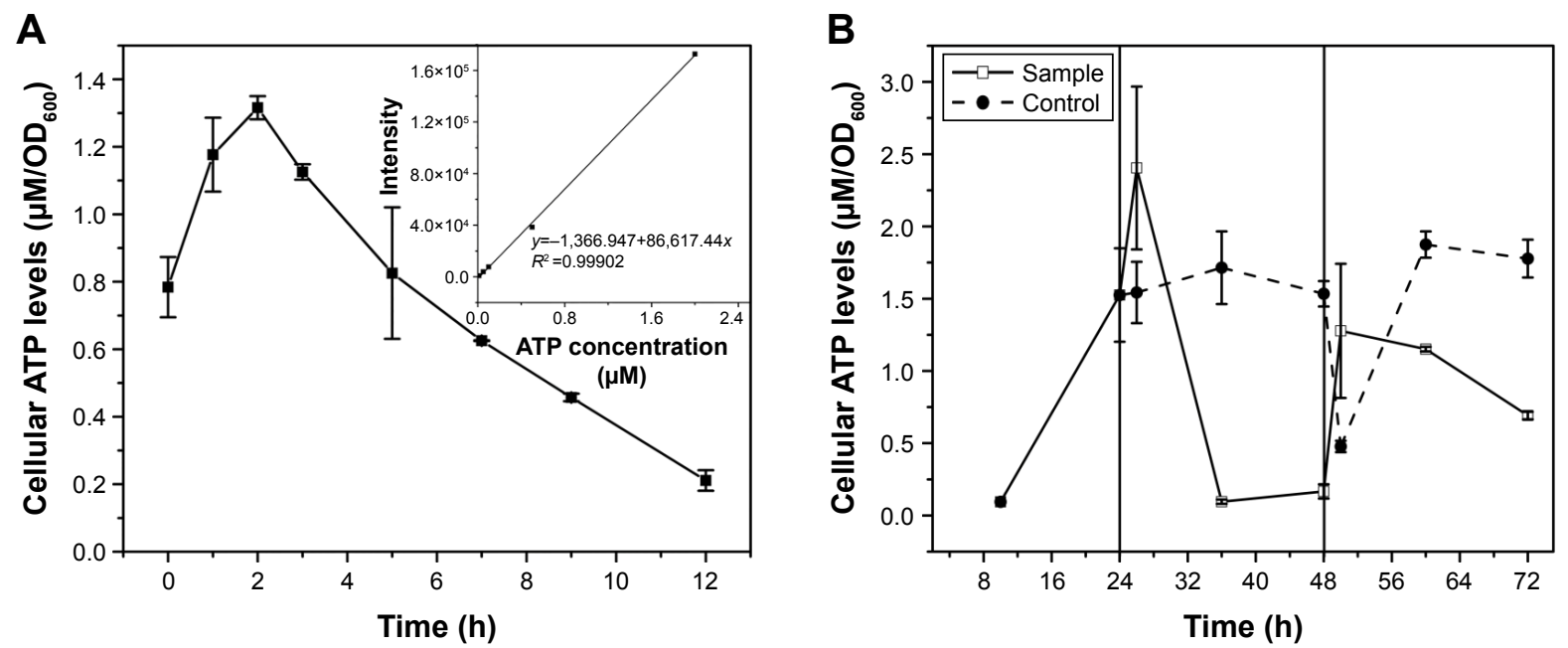

Figure I Intracellular ATP concentrations during CdSe QDs biosynthesis.

Notes: (A) ATP concentrations during the 12-hour incubation with $\mathrm{Na}_{2} \mathrm{SeO}_{3}$; (B) ATP concentrations at different collection times during the whole process, from the cells in exponential phase to 24 hours after seleniumized cells were co-incubated with $\mathrm{CdCl}_{2}$. Vertical lines divide the process into three phases. The cell's growing phase is from 0 to 24 hours; $\mathrm{Na}_{2} \mathrm{SeO}_{3}$ was added at 24 hours. At 48 hours, cell pellets were transferred to fresh medium and $\mathrm{CdCl}_{2}$ was added to the culture.

Abbreviations: OD, optical density; QDs, quantum dots. 
A

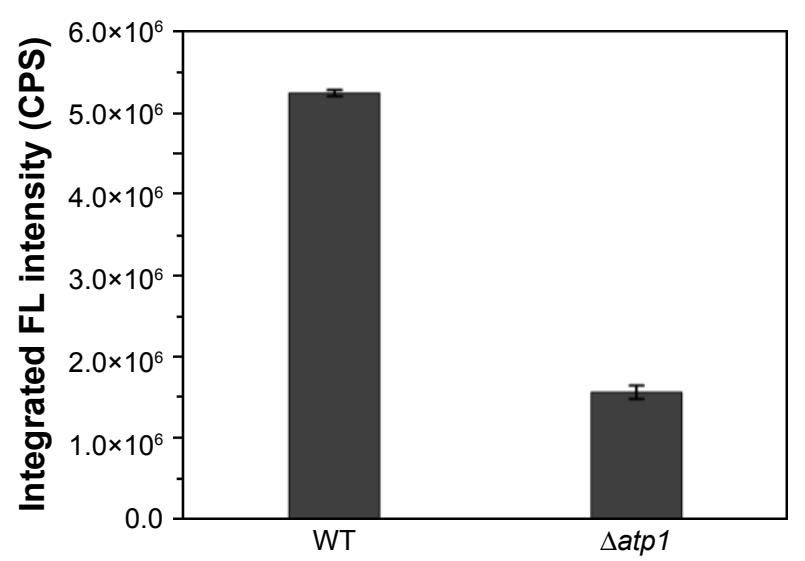

C

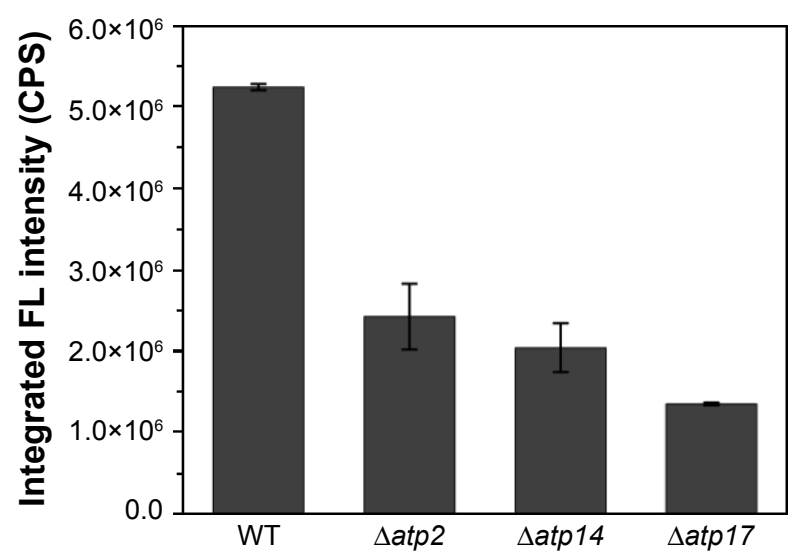

B

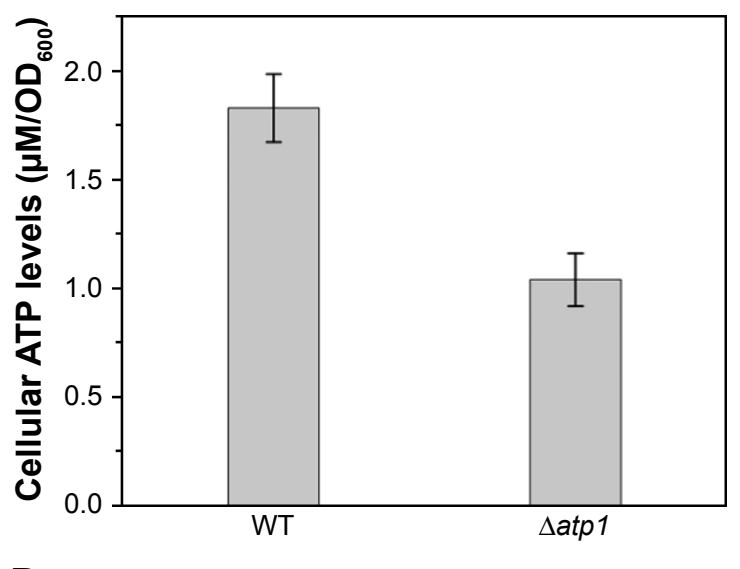

D

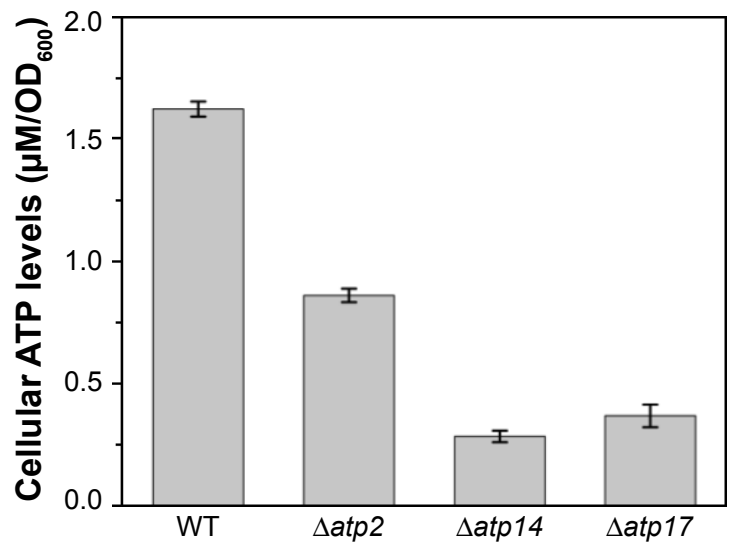

Figure 2 (A) Intracellular fluorescence intensities and (B) ATP concentrations of WT and $\Delta a t p /$ cells, (C) intracellular fluorescence intensities and (D) ATP concentrations of some ATP-synthesis-deficient strains.

Abbreviations: CPS, counts per second; FL, fluorescence; OD, optical density; WT, wild-type.

ATP concentrations and QDs fluorescence intensities than for WT cells (Figure 2C and D). The fluorescence intensities of $\Delta a t p 2, \Delta a t p 14$, and $\Delta a t p 17$ cells were $1 / 2,2 / 5$, and $1 / 4$ (Figure $2 \mathrm{C}$ ) of the WT cells, whereas the ATP concentrations were $1 / 2,1 / 10$, and $1 / 8$ (Figure 2D) of the WT cells, respectively. The fluorescence intensities roughly conformed to the intracellular ATP concentrations.

\section{Total intracellular GSH of the $\Delta a t p I$ strain and its QDs synthesis ability}

As to the specific reason for the influence of ATP on QDs biosynthesis, we suspected it was due to effects on intracellular GSH synthesis. In our previous study, we found that GSH was important for the QDs biosynthesis and the intracellular GSH content showed synchronized increase with the fluorescence intensity, ${ }^{26,27}$ so the GSH contents were checked in this study too. Interestingly, when the total GSH concentrations were measured in the $\Delta a t p 1$ strain after seleniumized cells were treated with $\mathrm{CdCl}_{2}$, that tendency referred to above disappeared. Instead, the GSH level kept steady around a certain value (about $9 \mu \mathrm{M}$ per $1 \mathrm{OD}_{600}$ cells) with only a slight fluctuation, yet somehow was higher than that of WT cells (Figure 3A). At time 0, when the $\mathrm{CdCl}_{2}$ was added to the culture, GSH concentrations in $\Delta a t p 1$ and WT cells were 6.72 and $2.95 \mu \mathrm{M}$ per $1 \mathrm{OD}_{600}$ cells, respectively. Nevertheless, GSH concentrations in the WT cells presented a trend of gradual increase with culturing time for seleniumized cells incubated with $\mathrm{CdCl}_{2}$. The intracellular fluorescence intensities, however, had the same tendency of gradual increase in both WT and $\Delta a t p 1$ strains, but with a growing difference between them (Figure 3B).

\section{Se and $\mathrm{Cd}$ concentrations during co-incubation with yeast cells while synthesizing QDs (ICP-AES and AAS assays)}

Both the intracellular and extracellular concentrations of Se and $\mathrm{Cd}$ were measured during the QDs biosynthesis processes of WT and $\Delta a t p 1$ strains. Within error, nearly all Se or Cd lost from the medium was absorbed into the 
A

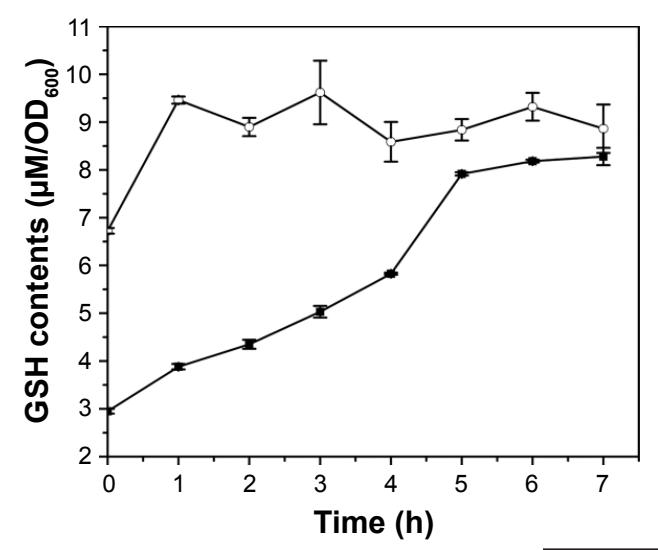

B

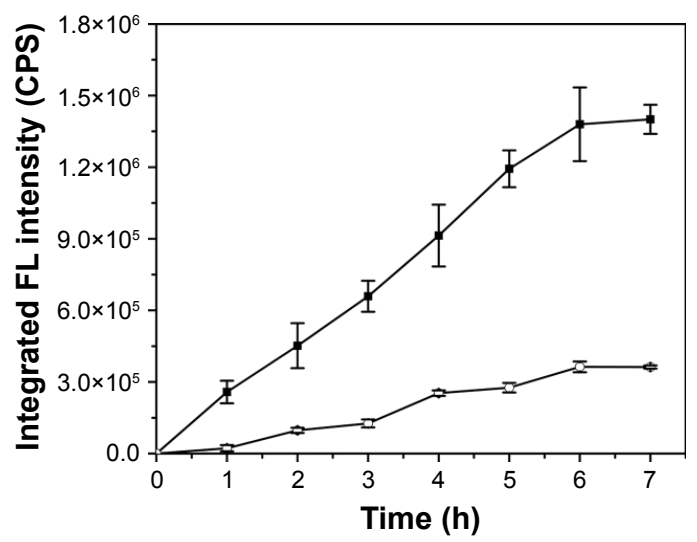

$\rightarrow$ WT $\longrightarrow$ - $\triangle$ atp1

Figure 3 Intracellular GSH contents $(\mathbf{A})$ and intracellular fluorescence intensities (B) of seleniumized WT and $\Delta a t p /$ cells incubated with CdCl ${ }_{2}$ during the first 7 hours. Abbreviations: CPS, counts per second; FL, fluorescence; GSH, glutathione (l- $\gamma$-glutamylcysteinylglycine); OD, optical density; WT, wild-type.

cells (Figure 4). Although compared with the amount of $\mathrm{Na}_{2} \mathrm{SeO}_{3}$ (final concentration of $2.5 \mathrm{mM}$ ) or $\mathrm{CdCl}_{2}$ (final concentration of $1 \mathrm{mM}$ ) added to the culture (which was the optimized amount for CdSe QDs biosynthesis, data not shown), WT and $\Delta a t p 1$ both just took a small amount inside the cells; they did have the same trend of absorption of both compounds (Figure 4). The differences were evident between WT and $\Delta a t p 1$ strains. The Se uptake of WT was quite conspicuous at first and then slowed down and stabilized after incubation for 12 hours, reaching a final concentration of $0.48 \pm 0.029 \mathrm{mM}$, whereas the Se concentration inside $\Delta a t p 1$ cells was negligible with a concentration of $0.04 \pm 0.016 \mathrm{mM}$. The intracellular Se differences between $\Delta a t p l$ and WT began to emerge 2 hours after the addition of $\mathrm{Na}_{2} \mathrm{SeO}_{3}$ and increased during the culturing over the following 24 hours (Figure 4A). A similar result was observed with the uptake of $\mathrm{Cd}$, the increase tendency of the two strains was the same, only with a lower concentration in $\Delta a t p l$ cells. The final concentration in $\Delta a t p 1$ cells was $0.10 \pm 0.004 \mathrm{mM}$, less than half of that in WT cells, which was $0.27 \pm 0.045 \mathrm{mM}$ (Figure 4B).

\section{Major seleno-amino acid determination in $\Delta a t p /$ and WT cells}

Seleniumized cells of WT and $\Delta a t p 1$ strains were collected, and their total proteins were extracted and digested to oligopeptides with trypsin to measure the main reduced Se species inside. On the basis of the previous study, ${ }^{26}$ organoSe compounds selenocystine $\left[(\mathrm{Se}-\mathrm{Cys})_{2}\right]$, Se-methylselenoL-cysteine (SeMC), and d,L-selenomethionine (Se-Met)
A

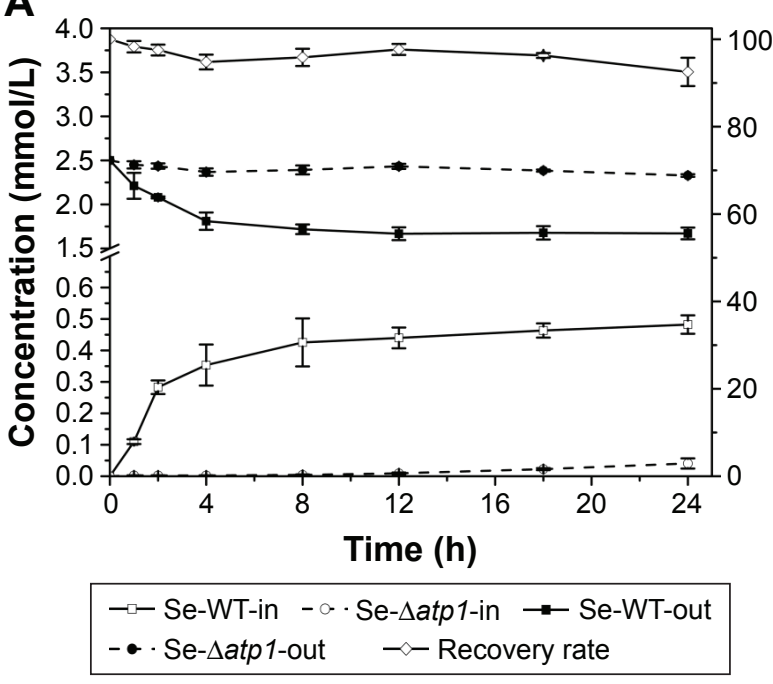

B

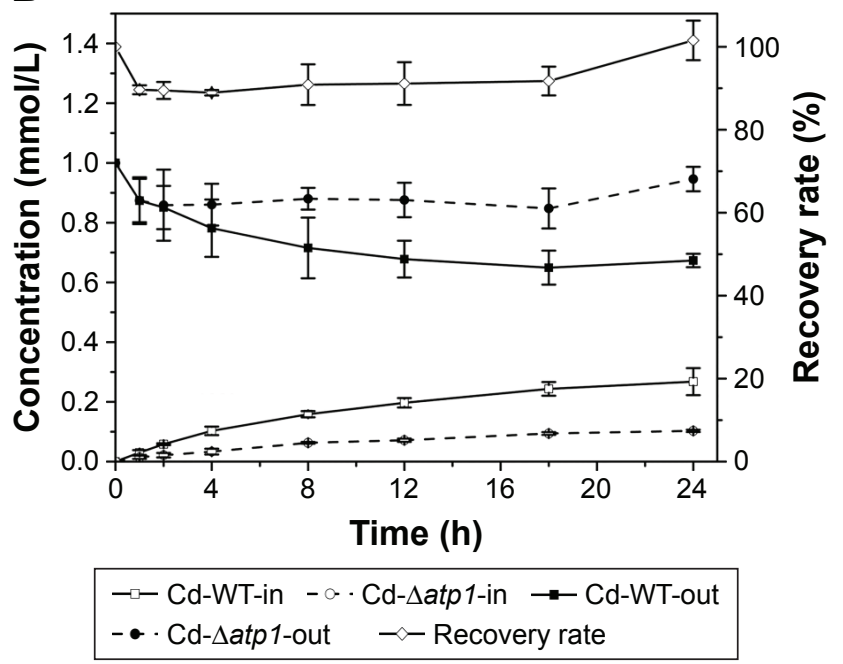

Figure $4 \mathrm{Se}$ (A) and Cd (B) concentrations inside (in) and outside (out) wild-type (WT) and $\Delta$ atp / cells, and the recovery rate of total Se or Cd added to the culture. Se/CdWT/Aatp /-in/out stands for Se/Cd concentrations inside/outside the WT/Aatp / cells. 


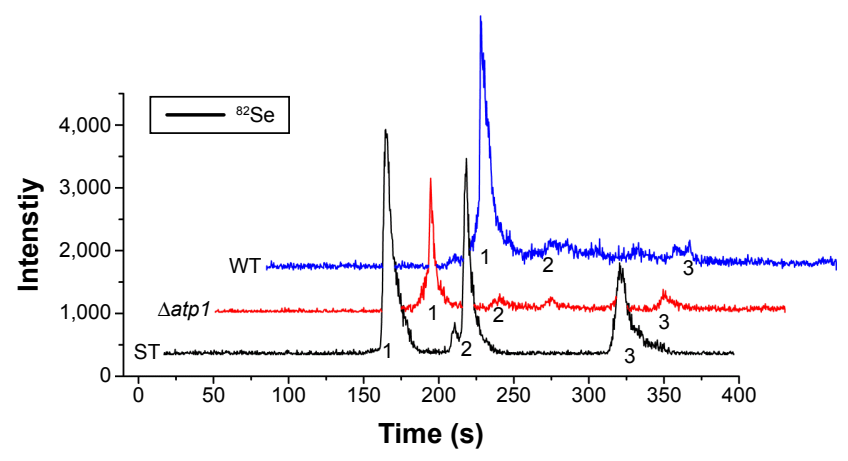

Figure 5 HPLC-ICP-MS chromatogram of Se species standards (ST) and selenoamino acids characterized from WT and $\Delta a t p /$ cells after treatment with $\mathrm{Na}_{2} \mathrm{SeO}_{3}$. The Se species standards are: I, L-selenocystine; 2, Se-methylseleno-L-cysteine; 3, d,L-selenomethionine.

Abbreviations: HPLC-ICP-MS, high-performance liquid chromatographyinductively coupled plasma mass spectrometry; WT, wild-type.

were checked. HPLC-ICP-MS showed that the major seleno-amino acid (Se-Cys) ${ }_{2}$ signal in the WT sample was obviously stronger than that in the $\Delta a t p 1$ sample (Figure 5). The peak height of (Se-Cys) in $\Delta a t p 1$ cells was half that of WT cells.

A

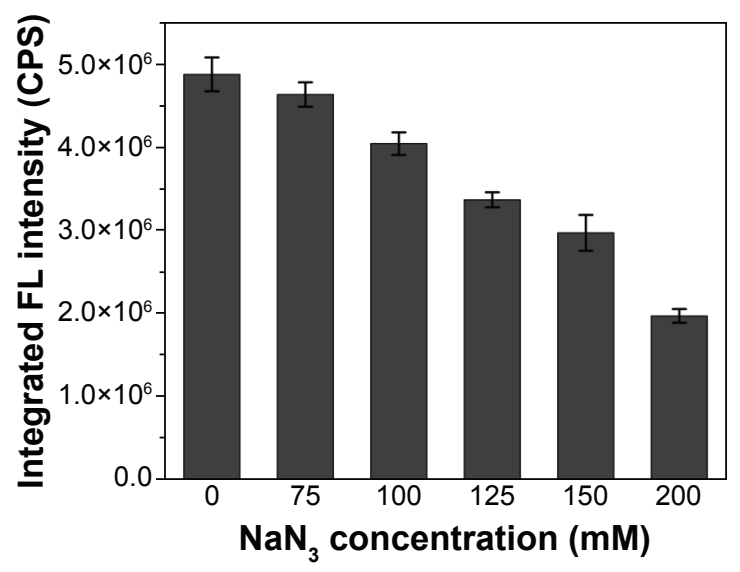

\section{CdSe QDs biosynthesis under the influences of oxidative phosphorylation inhibitor or uncoupler}

To investigate the effects of ATP on the absorption of $\mathrm{Cd}$ and QDs crystallization, the intracellular fluorescence intensities of cells under different concentrations of oxidative phosphorylation inhibitor $\left(\mathrm{NaN}_{3}\right)$ or uncoupler $(2,4-$ dinitrophenol, DNP), which were added to the culture during the incubation of seleniumized cells with $\mathrm{CdCl}_{2}$, were measured. The results in Figure $6 \mathrm{~A}$ show that the intracellular fluorescence intensities decreased to less than half of the normal value along with the increase in the $\mathrm{NaN}_{3}$ concentrations from 75 to $200 \mathrm{mM}$, indicating the remarkable influence of the addition of $\mathrm{NaN}_{3}$ on QDs biosynthesis. When DNP was introduced into the culture, intracellular fluorescence intensities had a slight yet noticeable reduction (Figure 6B). At the same time, Cd concentrations of seleniumized cells incubated with $\mathrm{CdCl}_{2}$ were checked in the presence of $150 \mathrm{mM} \mathrm{NaN}_{3}$ or $2 \mathrm{mM}$ DNP, with concentrations that had visible impacts on CdSe QDs

B

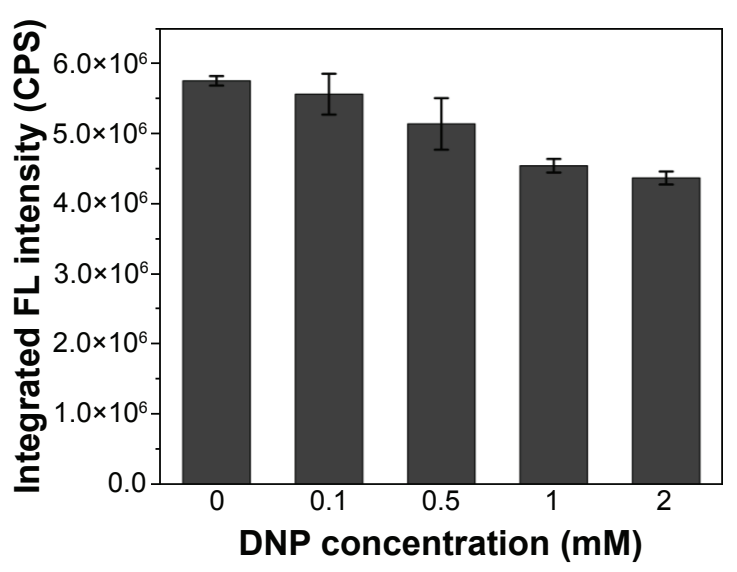

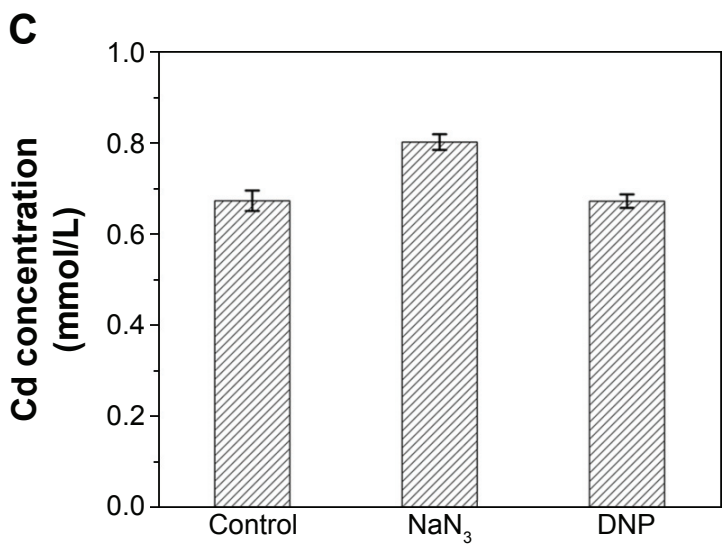

Figure 6 Intracellular fluorescence intensities of WT cells treated with different concentrations of $\mathrm{NaN}_{3}(\mathbf{A})$ or DNP $(\mathbf{B})$, and Cd concentrations in the culture supernatants of cells samples treated with $150 \mathrm{mM} \mathrm{NaN}_{3}$ and $2 \mathrm{mM} \mathrm{DNP}(\mathbf{C})$ and when co-incubated with $\mathrm{CdCl}_{2}$.

Abbreviations: DNP, 2,4-dinitrophenol; FL, fluorescence; WT, wild-type. 
A

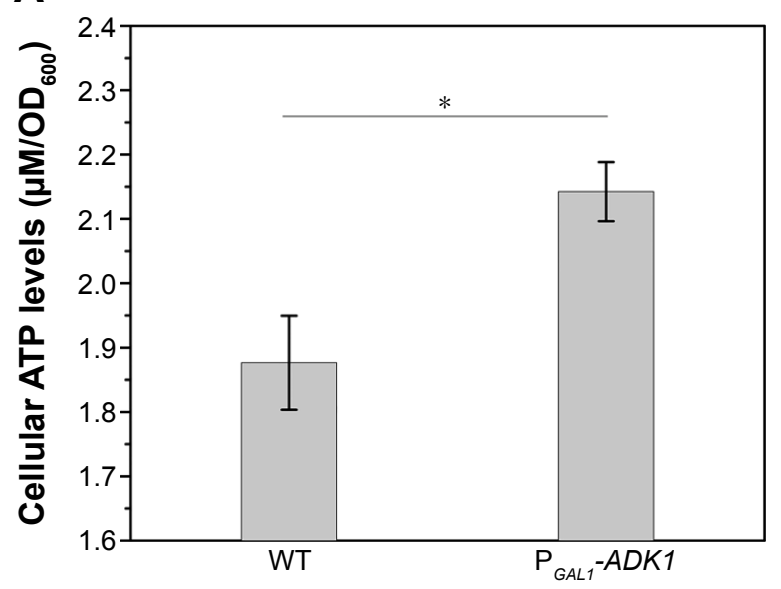

B

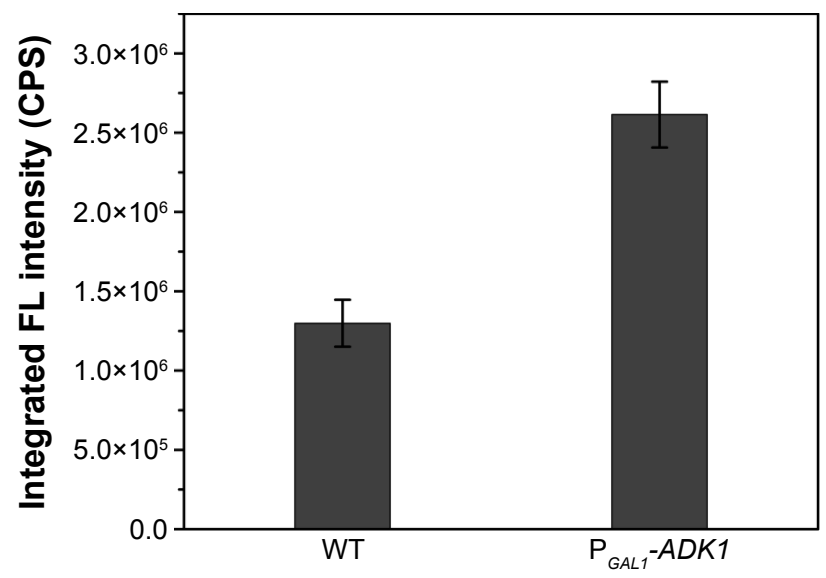

Figure 7 Intracellular ATP concentrations $(\mathbf{A})$ and $\mathrm{FL}$ intensities $(\mathbf{B})$ of $\mathrm{WT}$ and $\mathrm{P}_{\text {GALL }}$-ADKI strains.

Notes: The results are expressed as mean \pm standard deviation, $n=3 . * P<0.05$.

Abbreviations: FL, fluorescence; OD, optical density; WT, wild-type.

biosynthesis (Figure 6C). Differences were not noticeable in the fluorescence intensities.

\section{QDs biosynthesis manipulation on the basis of ATP synthesis}

To investigate the use of energy influence in the manipulation of biosynthesis, genetic modification of the energy metabolism pathway was introduced. Overexpression of the $A D K 1$ gene leads to an accumulation of ATP levels inside the cells. When the promoter of $A D K 1$ gene was replaced with a stronger promoter, the intracellular ATP concentration increased nearly two times (Figure 7A). Figure 7B shows that the intracellular fluorescence intensity was twice that in the WT cells.

\section{Discussion}

This study was approached to determine the specific influence of energy on CdSe QDs biosynthesis by yeast and took advantage of it to manipulate the biosynthesis process, for the reason that most of the proteins that encapsulated the QDs were functioned in cell energy metabolism (with the result of bioinformatics analysis, data not shown).

According to Li et al, ${ }^{27}$ the system in the present work uses "temporally-spatially coupling strategy" to biosynthesize CdSe QDs. Within this system, there are three phases: the cell-growing phase, the cell-seleniumized phase, and the CdSe QDs crystallization phase. Herein, the influence of ATP on the biosynthesis is carried out through the three crucial phases and mainly through the latter two phases.

To confirm the importance of the influence of ATP on biosynthesis, the intracellular ATP concentrations were determined. The ATP levels had significant variations not only in the cell-seleniumized phase (Figure 1A) but also in the whole procedure (Figure 1B). In contrast, the intracellular ATP concentrations of the control group (Figure 1B) were consistent with the cell growing state. ${ }^{34}$ To further confirm our suspicions, we used ATP-synthesis-deficient strains ( $\Delta a t p 1$, $\Delta a t p 2, \Delta a t p 14$, and $\Delta a t p 17)$ to biosynthesize CdSe QDs. The fluorescence intensities of the strains were as expected (Figure 2A and C). The fluorescence intensities and ATP concentrations of $\Delta a t p 2, \Delta a t p 14$, and $\Delta a t p 17$ (fermentationrelated genes were not taken into consideration because cells were not undertaking fermentative metabolism to generate ATP in the cell-seleniumized phase, Figures S3 and S4) were not exactly accordant (Figure 2C and D), which may be due to other influential factors. In this case, we proposed that CdSe QDs biosynthesis by yeast cells is an energy-consuming process, besides having many other necessary conditions. ${ }^{27}$ In the quasi-biosystem referred to by $\mathrm{Gu}$ et al, ${ }^{35}$ they only need several substrates and co-factors to synthesize nanomaterials, but the temperature must reach at least $80^{\circ} \mathrm{C}-90^{\circ} \mathrm{C}$, which was significantly higher than that for the biosynthesis. Hence, it may suggest that ATP synthesis inside the cells meets with the request of energy in the biosynthesis.

As already reported, GSH synthesis is an energyconsuming process. ${ }^{36}$ It was reasonable to hypothesize that the ATP effects may be due to its influence on the synthesis of GSH with its important role in our system. ${ }^{26,27}$ Interestingly, when the GSH contents were determined in the $\Delta a t p 1$ strain, the tendency of GSH levels increasing with fluorescence intensities, referred to above, did not appear (Figure 3A). The content level was higher than that of WT cells during the testing period, which may be because the addition of $\mathrm{CdCl}_{2}$ in seleniumized cells stimulated an increase of GSH. ${ }^{37}$ And because the addition of $\mathrm{Na}_{2} \mathrm{SeO}_{3}$ would trigger the upregulation of $\mathrm{GSH},{ }^{27}$ with lower intracellular Se concentration, the 
GSH cannot be used effectively ${ }^{38}$ and results in the higher GSH content in $\Delta a t p 1$ cells at time 0 than that of WT cells. These results (Figure $3 \mathrm{~A}$ and $\mathrm{B}$ ) attested that within the low ATP synthesis strains (such as $\Delta a t p 1$ ) mentioned, it was the utilization rather than synthesis of GSH that was impeded by the ATP levels.

With the results above, it was shown that ATP had a significant influence on CdSe QDs biosynthesis by yeast. Determining where ATP had its effects was important and urgent for its not insignificant role in the biosynthesis. Since there were two critical phases in the biosynthesis process, the influences of ATP were investigated through these two phases. Figure 4 shows the intracellular and the extracellular concentrations of the Se or $\mathrm{Cd}$ measured during the cell-seleniumized phase or the crystallization phase. The shortage of ATP synthesis caused an absorption deficiency of both elements constructing CdSe QDs, resulting in poor fluorescence intensity. We suspected this could be linked to the way that $\mathrm{SeO}_{3}{ }^{2-}$ or $\mathrm{Cd}^{2+}$ entered the cells, which might need ATP. ${ }^{39,40}$

Once inside the cells, $\mathrm{Se}(+4)$ ions are reduced to $\mathrm{Se}(-2)$ ions, then the $\mathrm{Cd}^{2+}$ interacts with the seleno-precursors and forms QDs crystals. The main seleno-amino acids emerging during the biosynthesis, as the previous study suggested, ${ }^{26}$ were detected by HPLC-ICP-MS. ${ }^{41}$ In Figure 5, it is shown that the major seleno-amino acid peak heights in $\Delta a t p 1$ and WT samples were consistent with the fluorescence intensities between them (Figure 2B). The result was proof that the accumulation of the seleno-precursor was an energy-consuming process. A similar conclusion was reached for the crystallization phase. For the reason that $\Delta a t p 1$ cells cannot normally accumulate seleno-precursors, the oxidative phosphorylation inhibitor and uncoupler were introduced into the system instead. Both the inhibitor and uncoupler could induce the decline of the intracellular ATP concentration, except that the uncoupler had no influence on oxidoreduction..$^{42,43}$ The introduction of the DNP (uncoupler) was to ensure that the reduction of the selenite was unaffected. It turned out that $\mathrm{NaN}_{3}$ had an evident impact on the crystallization (Figure 6A), whereas DNP had a lesser yet noticeable influence (Figure 6B). Under their influence, the uptake of $\mathrm{Cd}$ was nearly impervious (Figure 6C) at the concentration when the intracellular ATP concentration became lower (Figure S5) (glycolysis inhibitor had been taken into consideration because the influence on ATP generation was not obvious, Figure S6). As a consequence, without altering the $\mathrm{Cd}$ absorption, the importance of ATP in the QDs crystallization was confirmed.

Thus, the specific influence of ATP was made clear. Figure 8 briefly describes the QDs biosynthesis process

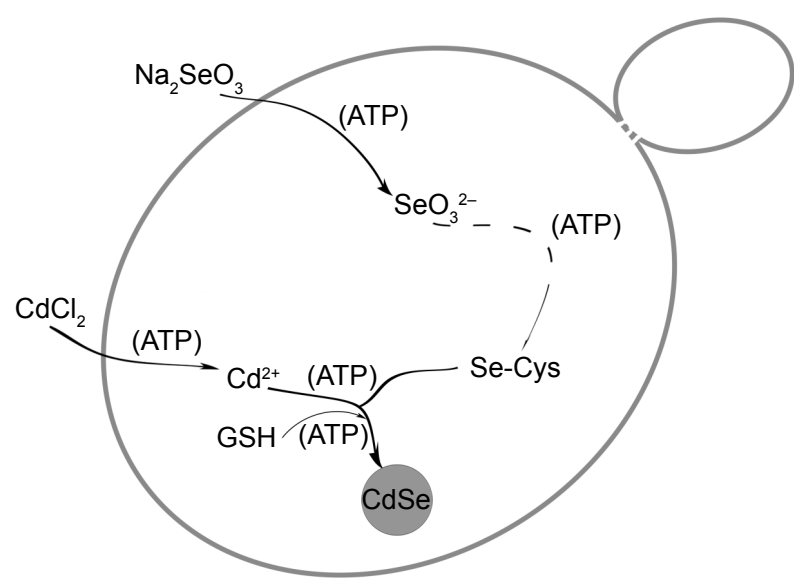

Figure 8 Schematic illustration of the points of action of ATP in the CdSe QDs biosynthesis process in Saccharomyces cerevisiae.

Abbreviations: GSH, glutathione (l- $\gamma$-glutamylcysteinylglycine); QDs, quantum dots.

in yeast and shows the points of ATP action. It shows that ATP guarantees the uptake of the two inorganic compounds, helps with the accumulation of the seleno-precursors, and facilitates the utilization of the GSH accumulated during the crystallization phase. As the most direct energy resource in the organisms, ATP plays indispensable roles in many biological processes, ${ }^{44,45}$ but its influence in the biosynthesis of nanomaterials has often been overlooked. With the present work, we have determined the difference between the intrinsic processes and the constructed ones, thus allowing better application of the connection to bilaterally control the biosynthesis process.

It was quite feasible that we could increase the production of the QDs through accumulation of intracellular ATP according to our findings. The overexpression of the $A D K 1$ gene leads to the augmentation of ATP content. ${ }^{46}$ Through standard genetic techniques, ${ }^{47}$ the $\mathrm{P}_{G A L 1}-A D K 1$ strain was constructed (Figures S7 and S8). The phenotype was confirmed (Figure 7A), and the fluorescence intensity was consistent with the ATP levels. As it was reported, $S$-adenosylmethionine (SAM), one of the intermediate species of the methionine and cysteine metabolism pathway, needs methionine as a substrate and ATP for synthesis under the action of acyltransferase. ${ }^{48}$ Its seleno analog, SeAM, the synthesis of which is also affected by ATP content, ${ }^{38}$ is believed to be an important intermediate compound in the biosynthesis of CdSe QDs in yeast (unpublished data). An increase in ATP could lead to the accumulation of SAM, and under Se-rich culture, it would be SeAM. By direct overexpression of SAM2 gene to achieve the SAM accumulation, a $\mathrm{P}_{G A L 1}-S A M 2$ strain was successfully constructed (Figures S7 and S9A), and the intracellular SAM content was checked (Figure S9B). Figure 9 shows that the fluorescence intensity of the 


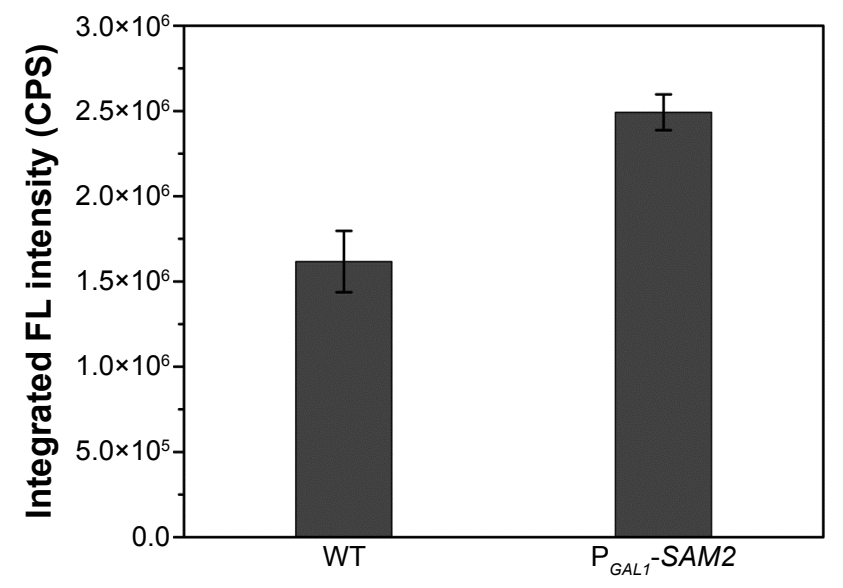

Figure 9 Intracellular fluorescence intensities of WT and $\mathrm{P}_{\text {GALI }}-\mathrm{SAM} 2$ strains. Abbreviations: FL, fluorescence; SAM, S-adenosylmethionine; WT, wild-type.

$\mathrm{P}_{\text {GALI }}$-SAM2 strain was about 1.5 times of that in the WT strain, which was consistent with the results of $\mathrm{P}_{G A L 1}-A D K 1$ strain. In summary, it does not matter whether the ATP content was indirectly increased or an intermediate compound in the process was directly increased, as it would give the same result, namely, a prominent increase in QDs biosynthesis ability.

\section{Conclusion}

In summary, we have uncovered a vital role of ATP played in the biosynthesis of CdSe QDs by yeast without changing the QDs fluorescent properties (Figures S10 and S11). Through investigating the specific interaction processes, the biosynthesis could be promoted simply by genetic modification of the WT strain. With the present work, we can integrate substance flux and energy flux ${ }^{49}$ in the biosynthesis process. To the best of our knowledge, the role of energy in the biosynthesis of nanoparticles in microorganisms has not been reported yet, and this is the first study that has focused on energy influence, filling the gap in the research about its mechanism. Other than complementation of the understanding of the biosynthesis process, what's more important is that this could offer a new perspective on the manipulation of nanoparticles biosynthesis using microorganisms aiding further applications.

\section{Acknowledgments}

This work was supported by the National Natural Science Foundation of China (21272182 and 31570090) and the National Basic Research Program of China (973 Program, number 2013CB933904). This project is partially supported by the Chinese 111 Project Grant B06018, the National Fund for Fostering Talents in Basic Sciences (J1103513), National Infrastructure of Natural Resources for Science and Technology Program of China (number NIMR-2015-8), and the Laboratory (Innovative) Research Fund of Wuhan University. We are grateful to XS Feng for ICP-AES and AAS measurement.

\section{Disclosure}

The authors report no conflicts of interest in this work.

\section{References}

1. Alivisatos AP. Semiconductor clusters, nanocrystals, and quantum dots. Science. 1996;271(5251):933-937.

2. Shinchi H, Wakao M, Nagata N, et al. Cadmium-free sugar-chainimmobilized fluorescent nanoparticles containing low-toxicity $\mathrm{ZnS}$ $\mathrm{AgInS}_{2}$ cores for probing lectin and cells. Bioconjug Chem. 2014; 25(2):286-295.

3. Gao X, Liu X, Lin Z, Liu S, Su X. CuInS ${ }_{2}$ quantum dots as a nearinfrared fluorescent probe for detecting thrombin in human serum. Analyst. 2012;137(23):5620-5624.

4. Liu LW, Hu R, Law WC, et al. Optimizing the synthesis of red- and near-infrared $\mathrm{CuInS}_{2}$ and $\mathrm{AgInS}_{2}$ semiconductor nanocrystals for bioimaging. Analyst. 2013;138(20):6144-6153.

5. Yong KT, Roy I, Hu R, et al. Synthesis of ternary $\mathrm{CuInS}_{2} / \mathrm{ZnS}$ quantum dot bioconjugates and their applications for targeted cancer bioimaging. Integr Biol (Camb). 2010;2(2-3):121-129.

6. Liu X, Ju H. Coreactant enhanced anodic electrochemiluminescence of CdTe quantum dots at low potential for sensitive biosensing amplified by enzymatic cycle. Anal Chem. 2008;80(14):5377-5382.

7. Liu X, Cheng L, Lei J, Liu H, Ju H. Formation of surface traps on quantum dots by bidentate chelation and their application in lowpotential electrochemiluminescent biosensing. Chemistry. 2010;16(35): 10764-10770

8. Nann T, Skinner WM. Quantum dots for electro-optic devices. ACS Nano. 2011;5(7):5291-5295.

9. Huang HH, Zhao FC, Liu LG, et al. Emulsion synthesis of sizetunable $\mathrm{CH}_{3} \mathrm{NH}_{3} \mathrm{PbBr}_{3}$ quantum dots: an alternative route toward efficient light-emitting diodes. ACS Appl Mater Interfaces. 2015;7(51): 28128-28133.

10. Penner RM. Hybrid electrochemical/chemical synthesis of quantum dots. Acc Chem Res. 2000;33(2):78-86.

11. Mandal D, Bolander ME, Mukhopadhyay D, Sarkar G, Mukherjee P. The use of microorganisms for the formation of metal nanoparticles and their application. Appl Microbiol Biotechnol. 2006;69(5):485-492.

12. Rodrigues AG, Ping LY, Marcato PD, et al. Biogenic antimicrobial silver nanoparticles produced by fungi. Appl Microbiol Biotechnol. 2013;97(2):775-782.

13. Dameron CT, Reese RN, Mehra RK, et al. Biosynthesis of cadmiumsulfide quantum semiconductor crystallites. Nature. 1989;338(6216): 596-597.

14. Hnain A, Brooks J, Lefebvre DD. The synthesis of elemental selenium particles by Synechococcus leopoliensis. Appl Microbiol Biotechnol. 2013;97(24):10511-10519.

15. Shankar SS, Ahmad A, Pasricha R, Sastry M. Bioreduction of chloroaurate ions by geranium leaves and its endophytic fungus yields gold nanoparticles of different shapes. J Mater Chem. 2003;13(7):1822-1826.

16. Bhainsa KC, D'Souza SF. Extracellular biosynthesis of silver nanoparticles using the fungus Aspergillus fumigatus. Colloids Surf B Biointerfaces. 2006;47(2):160-164.

17. Shankar SS, Rai A, Ahmad A, Sastry M. Rapid synthesis of Au, Ag, and bimetallic Au core-Ag shell nanoparticles using Neem (Azadirachta indica) leaf broth. J Colloid Interface Sci. 2004;275(2):496-502.

18. Chandran SP, Chaudhary M, Pasricha R, Ahmad A, Sastry M. Synthesis of gold nanotriangles and silver nanoparticles using Aloe vera plant extract. Biotechnol Prog. 2006;22(2):577-583.

19. Tan LJ, Wan AJ, Li HL. Synthesis of near-infrared quantum dots in cultured cancer cells. ACS Appl Mater Interfaces. 2014;6(1):18-23. 
20. Stürzenbaum SR, Höckner M, Panneerselvam A, et al. Biosynthesis of luminescent quantum dots in an earthworm. Nat Biotechnol. 2013; 8(1):57-60.

21. Xiong LH, Cui R, Zhang ZL, et al. Uniform fluorescent nanobioprobes for pathogen detection. ACS Nano. 2014;8(5):5116-5124.

22. Ayano H, Kuroda M, Soda S, Ike M. Effects of culture conditions of Pseudomonas aeruginosa strain RB on the synthesis of CdSe nanoparticles. J Biosci Bioeng. 2015;119(4):440-445.

23. Gericke M, Pinches A. Microbial production of gold nanoparticles. Gold bulletin. 2006;39(1):22-28.

24. Jha AK, Prasad K, Prasad K. A green low-cost biosynthesis of $\mathrm{Sb}_{2} \mathrm{O}_{3}$ nanoparticles. Biochem Eng J. 2009;43(3):303-306.

25. Vetchinkina EP, Loshchinina EA, Vodolazov IR, Kursky VF, Dykman LA, Nikitina VE. Biosynthesis of nanoparticles of metals and metalloids by basidiomycetes. Preparation of gold nanoparticles by using purified fungal phenol oxidases. Appl Microbiol Biotechnol. 2017; 101(3):1047-1062.

26. Cui R, Liu HH, Xie HY, et al. Living yeast cells as a controllable biosynthesizer for fluorescent quantum dots. Adv Funct Mater. 2009; 19(15):2359-2364.

27. Li Y, Cui R, Zhang P, et al. Mechanism-oriented controllability of intracellular quantum dots formation: the role of glutathione metabolic pathway. ACS Nano. 2013;7(3):2240-2248.

28. Xiong LH, Cui R, Zhang ZL, et al. Uniform fluorescent nanobioprobes for pathogen detection. ACS Nano. 2014;8(5):5116-5124.

29. Kruger NJ. The Bradford method for protein quantitation. Methods Mol Biol. 1994;34:9-15.

30. Takeda M, Chen WJ, Saltzgaber J, Douglas MG. Nuclear genes encoding the yeast mitochondrial ATPase complex. Analysis of ATP1 coding the F1-ATPase alpha-subunit and its assembly. J Biol Chem. 1986;261(32):15126-15133.

31. Saltzgaber-Muller J, Kunapuli SP, Douglas MG. Nuclear genes coding the yeast mitochondrial adenosine triphosphatase complex. Isolation of ATP2 coding the F1-ATPase beta subunit. J Biol Chem 1983;258(19):11465-11470.

32. Arselin G, Vaillier J, Graves PV, Velours J. ATP synthase of yeast mitochondria. Isolation of the subunit $\mathrm{h}$ and disruption of the ATP14 gene. J Biol Chem. 1996;271(34):20284-20290.

33. Spannagel C, Vaillier J, Arselin G, Graves PV, Velours J. The subunit f of mitochondrial yeast ATP synthase. Characterization of the protein and disruption of the structural gene ATP17. Eur J Biochem. 1997; 247(3):1111-1117.

34. Weiss A, Delproposto J, Giroux CN. High-throughput phenotypic profiling of gene-environment interactions by quantitative growth curve analysis in Saccharomyces cerevisiae. Anal Biochem. 2004; $327(1): 23-34$
35. Gu YP, Cui R, Zhang ZL, Xie ZX, Pang DW. Ultrasmall near-infrared $\mathrm{Ag}_{2} \mathrm{Se}$ quantum dots with tunable fluorescence for in vivo imaging. J Am Chem Soc. 2012;134(1):79-82.

36. Kiriyama K, Hara KY, Kondo A. Oxidized glutathione fermentation using Saccharomyces cerevisiae engineered for glutathione metabolism. Appl Microbiol Biotechnol. 2013;97(16):7399-7404.

37. Adamis PD, Mannarino SC, Eleutherio EC. Glutathione and gammaglutamyl transferases are involved in the formation of cadmiumglutathione complex. FEBS Lett. 2009;583(9):1489-1492.

38. Kieliszek M, Blazejak S, Gientka I, Bzducha-Wrobel A. Accumulation and metabolism of selenium by yeast cells. Appl Microbiol Biotechnol. 2015;99(13):5373-5382.

39. McDermott JR, Rosen BP, Liu ZJ. Jen 1p: a high affinity selenite transporter in yeast. Mol Biol Cell. 2010;21(22):3934-3941.

40. Gomes DS, Fragoso LC, Riger CJ, Panek AD, Eleutherio ECA. Regulation of cadmium uptake by Saccharomyces cerevisiae. BBA Gen Subjects. 2002;1573(1):21-25.

41. Guo XQ, He M, Nan K, Yan H, Chen BB, Hu B. A dual extraction technique combined with HPLC-ICP-MS for speciation of selenoamino acids in rice and yeast samples. J Anal At Spectrom. 2015; 31(2):406-414.

42. Judah JD. The action of 2:4-dinitrophenol on oxidative phosphorylation. Biochem J. 1951;49(3):271-285.

43. Stannard JN, Horecker BL. The in vitro inhibition of cytochrome oxidase by azide and cyanide. Fed Proc. 1947;6(172):599-608.

44. Liu LM, Li Y, Du GC, Chen J. Increasing glycolytic flux in Torulopsis glabrata by redirecting ATP production from oxidative phosphorylation to substrate-level phosphorylation. J Appl Microbiol. 2006;100(5):1043-1053.

45. Zhou J, Liu L, Chen J. Improved ATP supply enhances acid tolerance of Candida glabrata during pyruvic acid production. J Appl Microbiol. 2011;110(1):44-53.

46. Sakai Y RT, Yonehara T, Kato N, Tani Y. High-level ATP production by a genetically-engineered Candida Yeast. Nat Biotechnol. 1994;12(3):291-293.

47. Longtine MS, McKenzie AI, Demarini DJ, et al. Additional modules for versatile and economical PCR-based gene deletion and modification in Saccharomyces cerevisiae. Yeast. 1998;14(10):953-961.

48. Chen H, Wang Z, Wang Z, Dou J, Zhou C. Improving methionine and ATP availability by MET6 and SAM2 co-expression combined with sodium citrate feeding enhanced SAM accumulation in Saccharomyces cerevisiae. World J Microbiol Biotechnol. 2016;32(4):1-10.

49. Kok Sd, Kozak BU, Pronk JT, van Maris AJ. Energy coupling in Saccharomyces cerevisiae: selected opportunities for metabolic engineering. FEMS Yeast Res. 2012;12(4):387-397. 


\section{Supplementary materials}

Table SI List of strains

\begin{tabular}{|c|c|c|}
\hline Strains & Genotype & Resources \\
\hline BY4742 & MAT $\alpha$ his3- $\Delta I$ leu2- $\Delta 0$ lys2- $\Delta 0$ ura3- $\Delta 0$ & EUROSCRAF \\
\hline$\Delta a t p l$ & MAT $\alpha$ his3- $\Delta I$ leu2- $\Delta 0$ lys2- $\Delta 0$ ura3- $\Delta 0$ atp I::KanMX4 & EUROSCRAF \\
\hline$\Delta a t p 2$ & MAT $\alpha$ his3- $\Delta$ I leu2- $\Delta 0$ lys2- $\Delta 0$ ura3- $\Delta 0$ atp2::KanMX4 & EUROSCRAF \\
\hline$\Delta a t p / 4$ & MAT $\alpha$ his3- $\Delta$ I leu2- $\Delta 0$ lys2- $\Delta 0$ ura3- $\Delta 0$ atp I 4::KanMX4 & EUROSCRAF \\
\hline$\Delta a t p / 7$ & MAT $\alpha$ his3- $\Delta /$ leu2- $\Delta 0$ lys2- $\Delta 0$ ura3- $\Delta 0$ atp I 7::KanMX4 & EUROSCRAF \\
\hline$P_{G A L I}-A D K I$ & MAT $\alpha$ his3- $\Delta I$ leu2- $\Delta 0$ lys $2-\Delta 0$ ura3- $\Delta 0 \mathrm{P}_{\text {GALL }}-A D K I:: \operatorname{KanMX6}$ & This study \\
\hline $\mathrm{P}_{\text {GALI }}-\mathrm{SAM2}$ & MAT $\alpha$ his3- $\Delta$ I leu2- $\Delta 0$ lys $2-\Delta 0$ ura3- $\Delta 0 \mathrm{P}_{\text {GALI }}-S A M 2:: K a n M X 6$ & This study \\
\hline
\end{tabular}

Note: EUROSCRAF, European Saccharomyces cerevisiae Archive for Functional Analysis (Bad Homburg, Germany).

Table S2 PCR primers used in this study

\begin{tabular}{|c|c|c|}
\hline Primer name & Purpose & Primer sequence \\
\hline \multirow[t]{2}{*}{ adk I pGALI pf } & $A D K I$ gene promoter substitution & TTTTTTTTGATTTTCGACTTTTTCACTCTGGCTAGTT \\
\hline & & TTATTACGCATATGAATTCGAGCTCGTTTAAAC \\
\hline \multirow[t]{2}{*}{ adkI pGALI pr } & $A D K I$ gene promoter substitution & TGACTTTACCAGAGAAACGTTAATGTTTCTTTATTAA \\
\hline & & AGCTCTCGTTTCTCATTTTGAGATCCGGGTTTT \\
\hline \multirow[t]{2}{*}{ sam2 pGALI pf } & SAM2 gene promoter substitution & AAGAAGGAGGTTATATCTGTCCTTTCTACAAAGTATT \\
\hline & & TTCGAGAATCTTGGAATTCGAGCTCGTTTAAAC \\
\hline \multirow[t]{2}{*}{ sam2 pGALI pr } & SAM2 gene promoter substitution & TTATGTTTGTATATTGTCGTAAATACTGGATATATTGA \\
\hline & & AGACAGTTATGTCATTTTTGAGATCCGGGTTTT \\
\hline adkI pGALI CKA & Certification of correct substitution & TGTCCTTATTCGCCCATTTT \\
\hline adkI pGALI CKB & Certification of correct substitution & TTTGGAGCTTGAGTACCTTT \\
\hline sam2 pGALI CKA & Certification of correct substitution & AGATATTAACCGAAGCCAAAATACC \\
\hline sam2 pGALI CKB & Certification of correct substitution & CTAAGCTCTTTTCATAGTGCAGACC \\
\hline F4 & Certification of correct substitution & GAATTCGAGCTCGTTTAAAC \\
\hline R2 & Certification of correct substitution & CATTTTGAGATCCGGGTTTT \\
\hline
\end{tabular}

Abbreviations: PCR, polymerase chain reaction; SAM, S-adenosylmethionine.

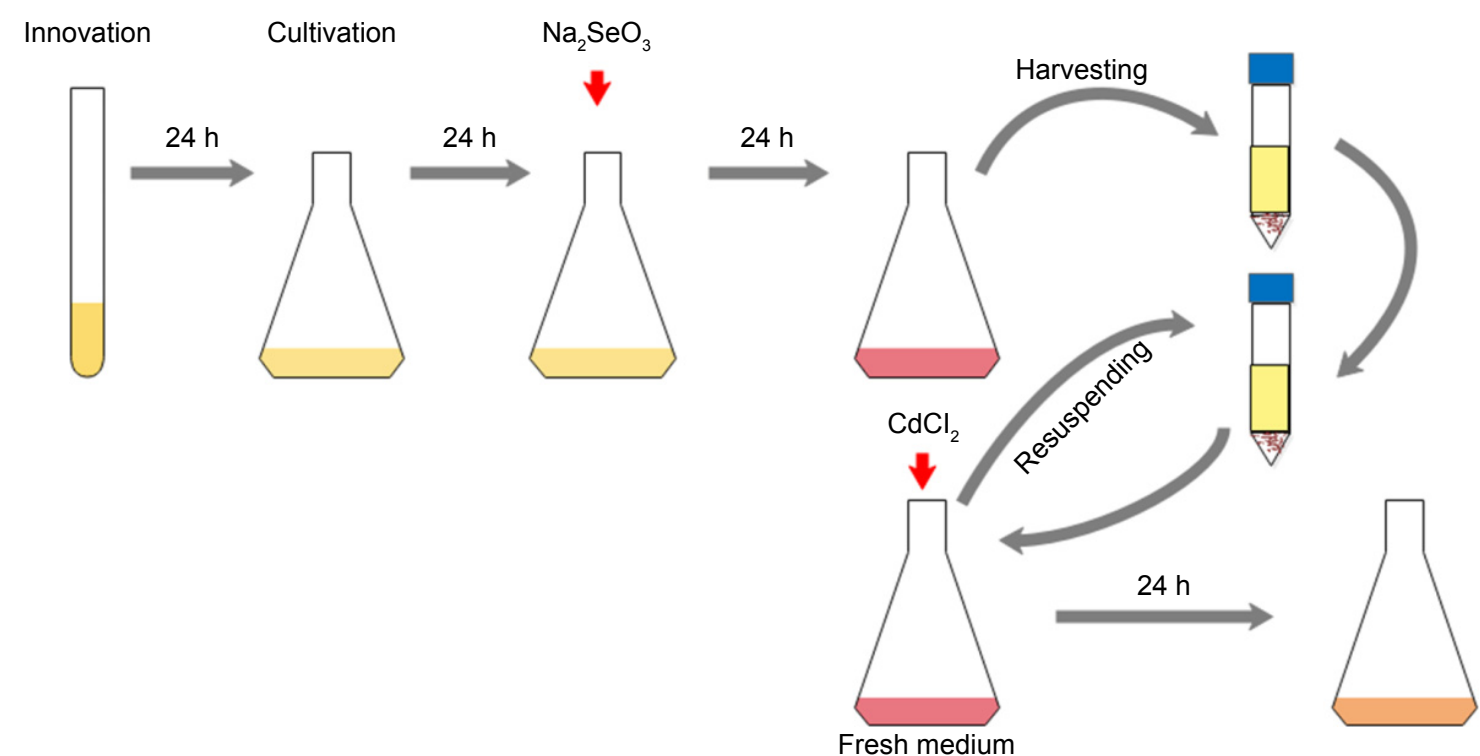

Figure SI Schematic flow chart of the biosynthetic procedure of the CdSe QDs in Saccharomyces cerevisiae.

Abbreviation: QDs, quantum dots. 

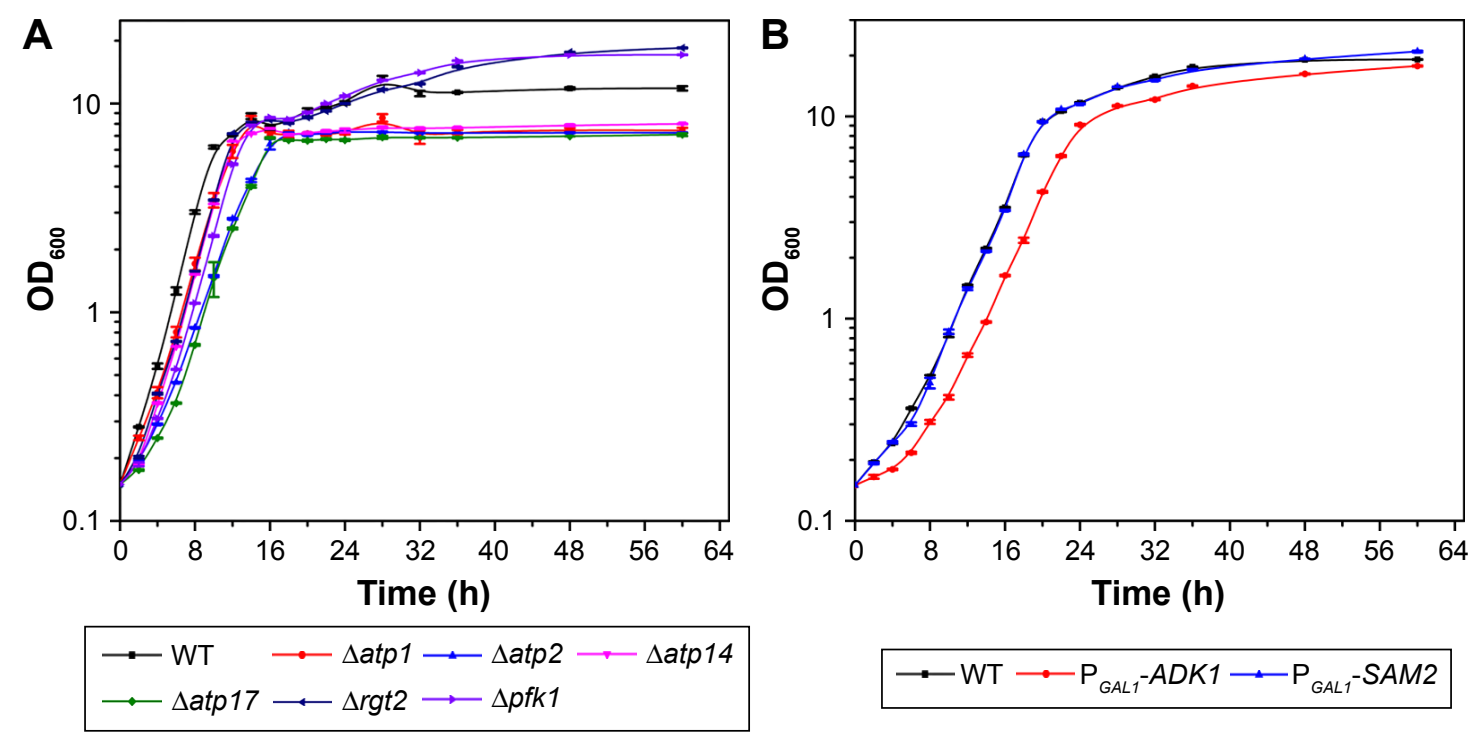

Figure S2 Growth curves of the strains in the present work cultured in YPGlu (A) or YPGal (B).

Abbreviations: OD, optical density; WT, wild-type; YP, I $\mathrm{g} \mathrm{L}^{-1}$ yeast extract and $2 \mathrm{~g} \mathrm{~L}^{-1}$ peptone; YPGlu, YP supplied with $2 \mathrm{~g} \mathrm{L^{-1 }}$ glucose; YPGal, YP supplied with $2 \mathrm{~g} \mathrm{~L}^{-1}$ galactose.

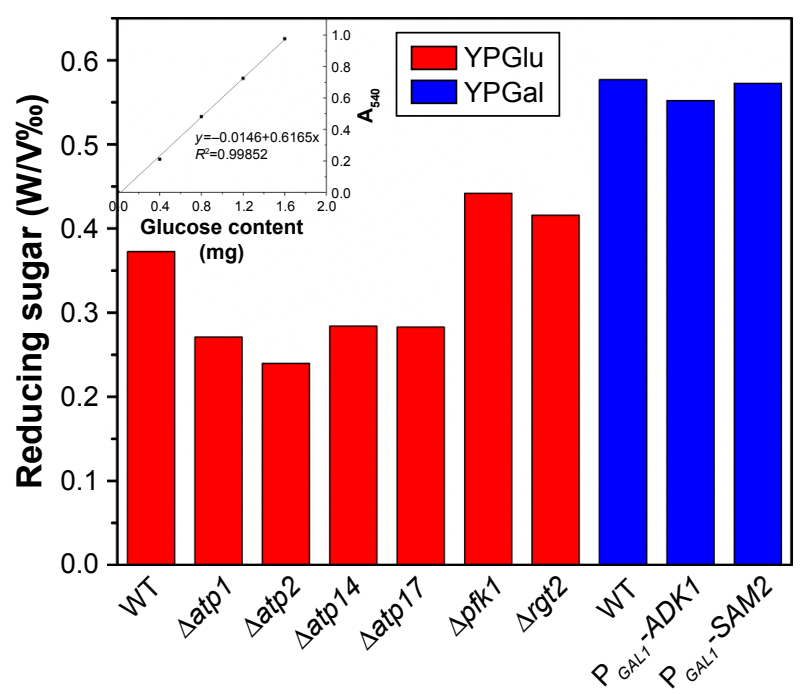

Figure S3 Sugar remaining in the supernatants of different strains after cultivation for 24 hours right before $\mathrm{Na}_{2} \mathrm{SeO}_{3}$ was added into the culture. Abbreviations: $\mathrm{A}_{540}$, absorbance; $\mathrm{OD}$, optical density; WT, wild-type.

A

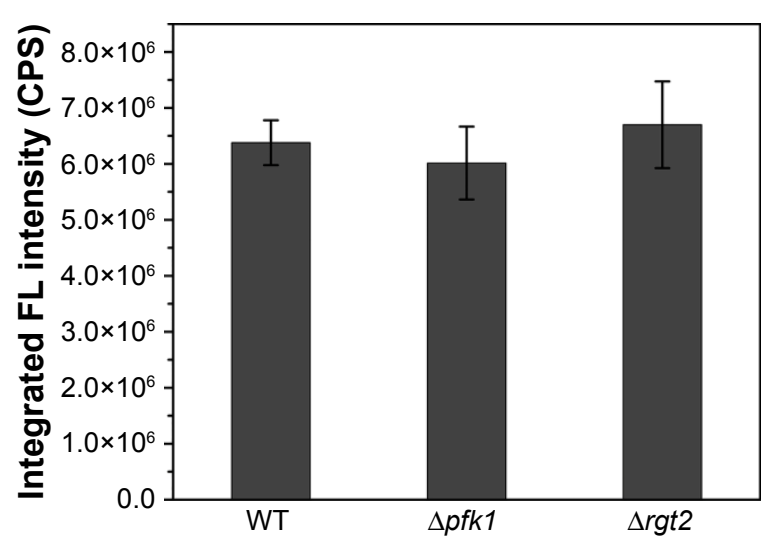

B

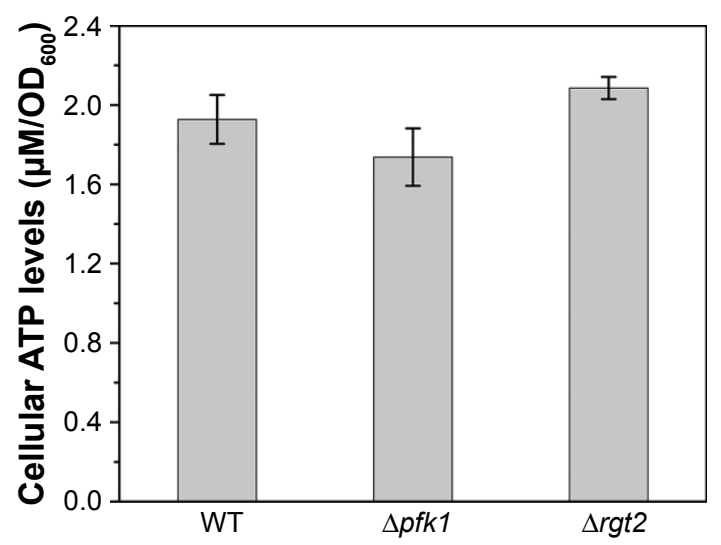

Figure S4 FL intensities (A) and intracellular ATP concentrations (B) of the WT, $\Delta p f k l$, and $\Delta$ rgt2. Abbreviations: CPS, counts per second; FL, fluorescence; OD, optical density; WT, wild-type. 


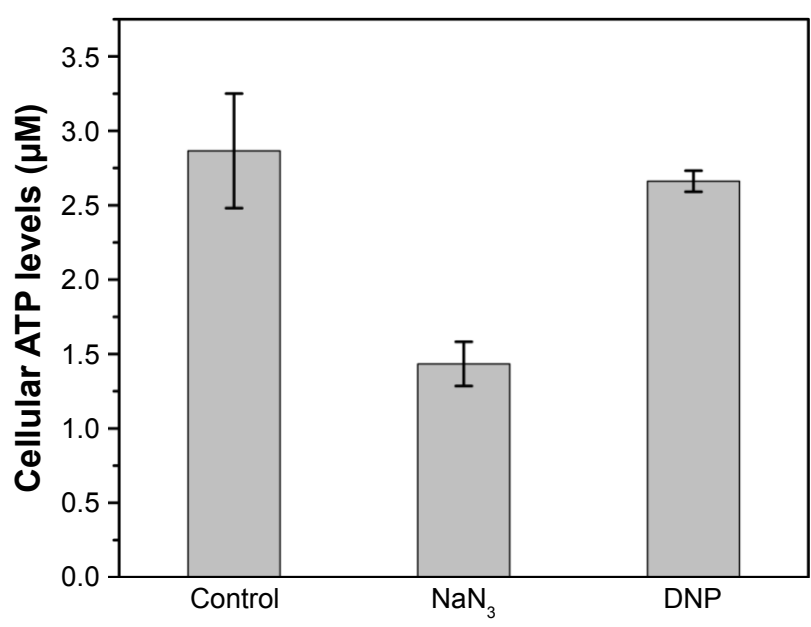

Figure S5 Intracellular ATP concentrations of WT samples and WT cells under the influences of $150 \mathrm{mM} \mathrm{NaN}_{3}$ or $2 \mathrm{mM} \mathrm{DNP.}$

Abbreviations: DNP, 2,4-dinitrophenol; WT, wild-type.

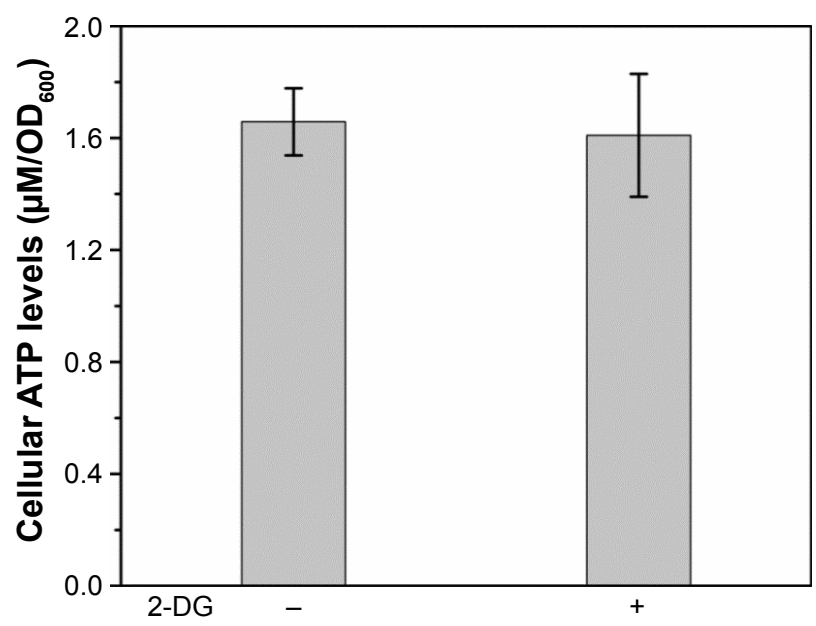

Figure S6 Intracellular ATP concentrations of the WT cells under the effect of $0.2 \%$ (wt/vol) 2-dexoglucose (2-DG) added with the introduction of $\mathrm{CdCl}_{2} \cdot-$, blank control without 2-DG; +, 0.2\% 2-DG into the culture.

Abbreviations: OD, optical density; WT, wild-type.

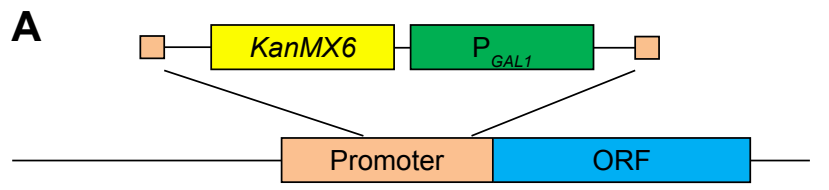

B

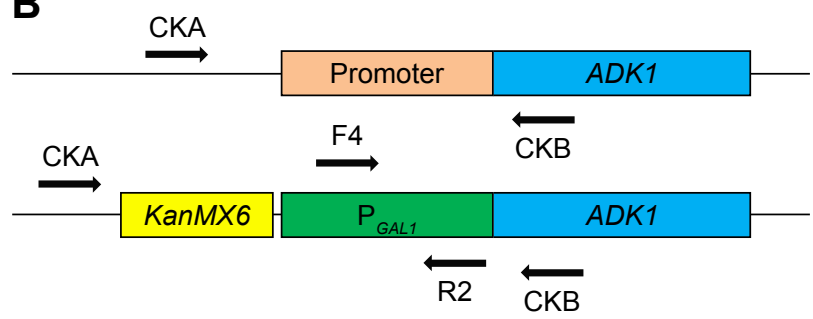

Figure $\mathbf{S 7}$ Schematic of the homologous recombination process $(\mathbf{A})$ and diagnostic polymerase chain reaction strategy (B). Gene specific primers CKA and CKB match the upstream and downstream of the insert site on the chromosome; F4 and R2 primers match the inner sequences of the insert DNA.

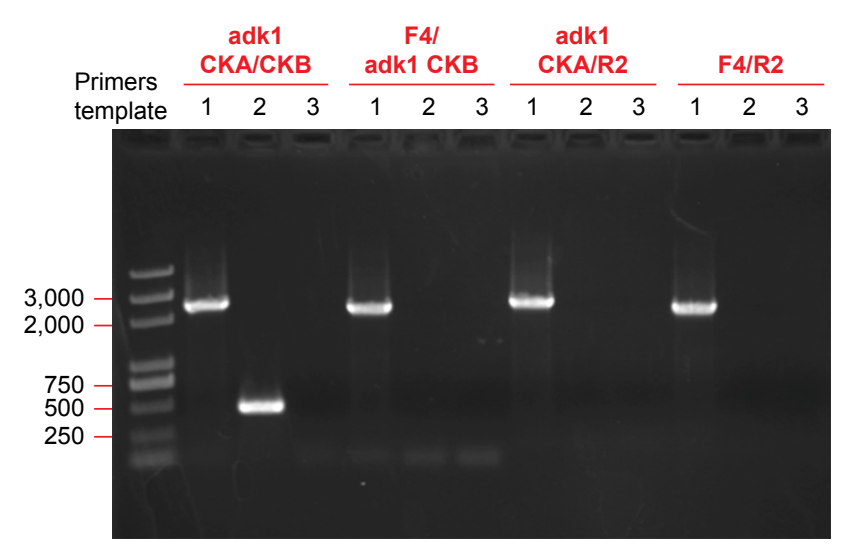

Figure S8 Diagnostic PCR electrophoresis image for confirming the correct replacement of the promoter of the $\mathrm{P}_{G A L}-A D K I$ strain, the primers used as referred, templates were: I, transformant genome; 2 , WT genome; 3 , no template control. Abbreviation: WT, wild-type.
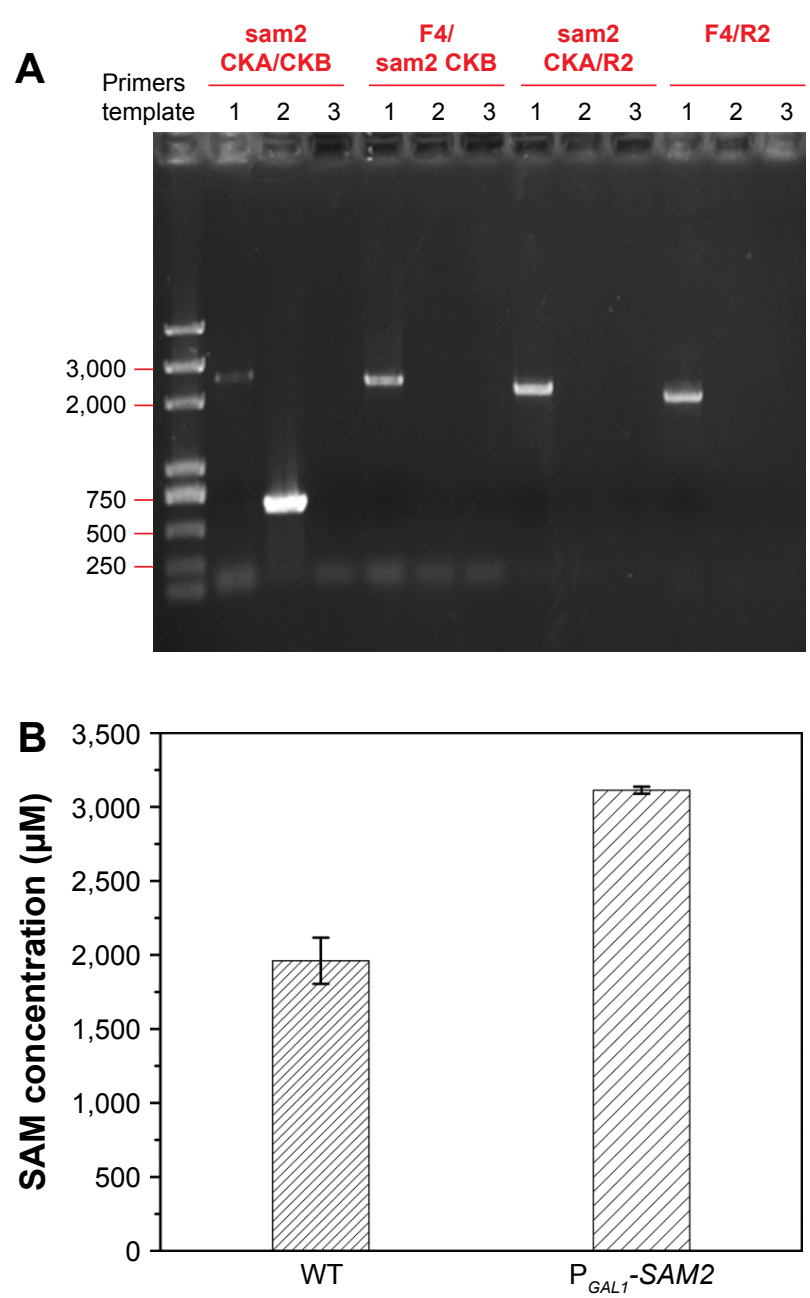

Figure S9 Electrophoresis image of the diagnostic PCR products using the primers referred to in Figure S7; templates were: I, transformant genome; 2, WT genome; 3, no template control (A), and intracellular SAM concentration of the WT and correct transformant cells (B).

Abbreviations: PCR, polymerase chain reaction; WT, wild-type. 


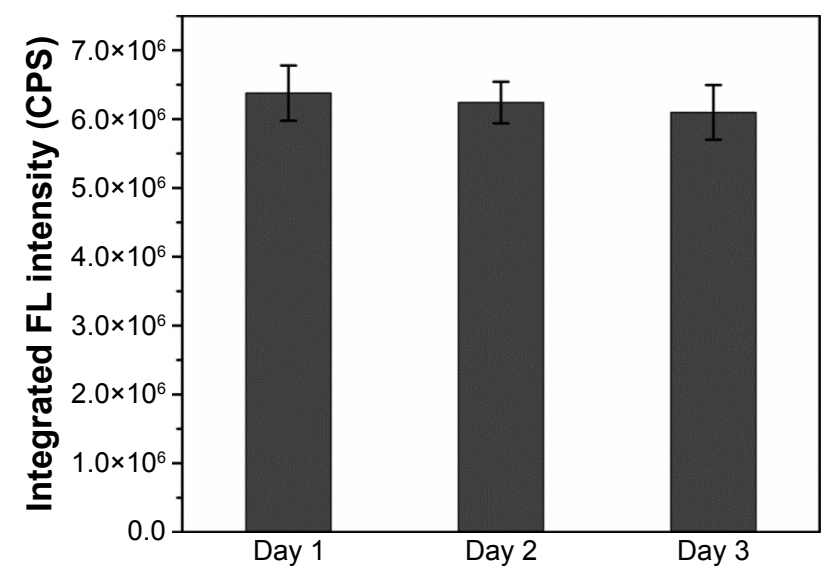

Figure SIO FL intensity of the same WT samples determined three times with a 24 hour interval. Abbreviations: CPS, counts per second; FL, fluorescence; WT, wild-type.

A

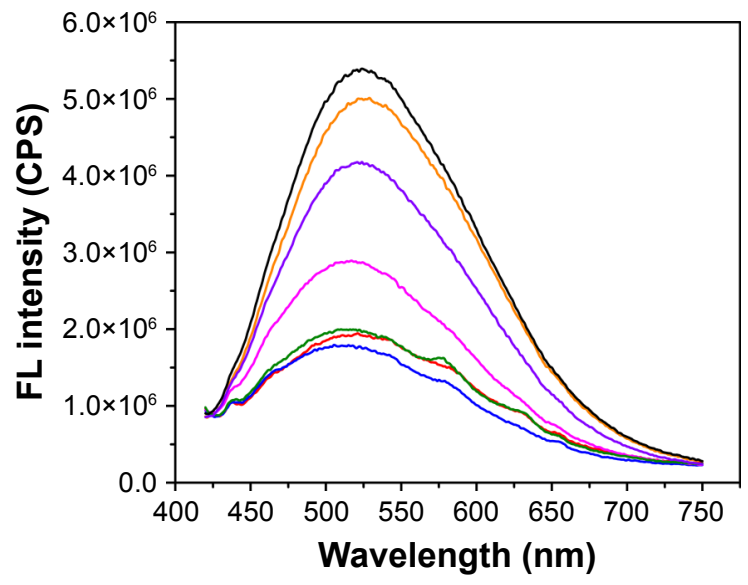

- WT $-\Delta \operatorname{atp} 1-\Delta$ atp2 $-\Delta$ atp14
$-\Delta$ atp17 $-\Delta$ rgt2 $-\Delta$ pfk1
B

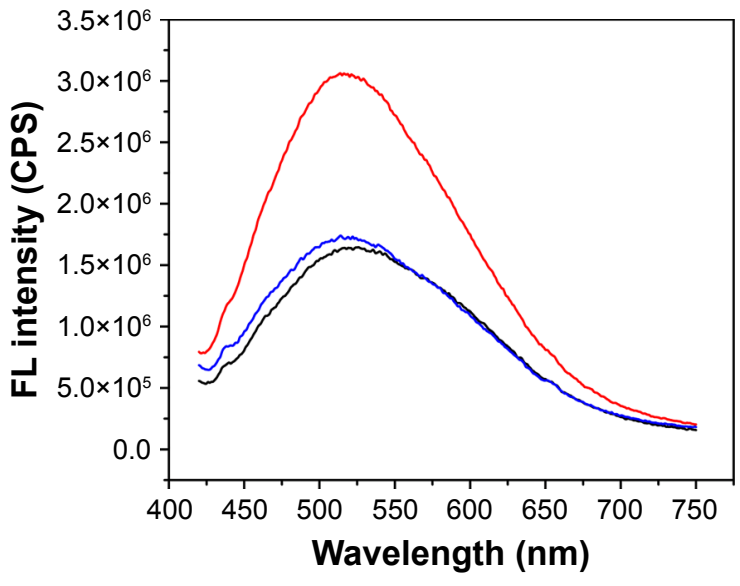

$-\mathrm{WT}-\mathrm{P}_{G A L 1}-A D K 1-\mathrm{P}_{G A L 1}-S A M 2$

Figure SI I Emission spectrums of the corresponding strains used in the present work cultured in YPGlu (A) or YPGal (B) medium. Abbreviations: CPS, counts per second; FL, fluorescence; WT, wild-type.

\section{Publish your work in this journal}

The International Journal of Nanomedicine is an international, peerreviewed journal focusing on the application of nanotechnology in diagnostics, therapeutics, and drug delivery systems throughou the biomedical field. This journal is indexed on PubMed Central, MedLine, CAS, SciSearch ${ }^{\circledR}$, Current Contents ${ }^{\circledR} /$ Clinical Medicine,
Journal Citation Reports/Science Edition, EMBase, Scopus and the Elsevier Bibliographic databases. The manuscript management system is completely online and includes a very quick and fair peer-review system, which is all easy to use. Visit http://www.dovepress.com/ testimonials.php to read real quotes from published authors. 